\title{
LA 'TERCERA MISIÓN’ DE LA UNIVERSIDAD, TRANSFERENCIA DE CONOCIMIENTO Y SOCIEDADES DEL CONOCIMIENTO. UNA APROXIMACIÓN DESDE LA PEDAGOGÍA
}

\author{
José Manuel Touriñán López \\ Universidad de Santiago de Compostela
}

\begin{abstract}
RESUMEN: La noción de sociedad de la información se basa en los progresos tecnológicos. En la sociedad del conocimiento, la ciencia se convierte en cuestión de Estado y el conocimiento se enfoca desde la perspectiva del desarrollo productivo de carácter social, cultural y económico.

Para la UNESCO, el hecho de referirse a sociedades, en plural, expresa la intención explícita de rechazar la unicidad de un modelo que no tenga suficientemente en cuenta la diversidad cultural y lingüística, único elemento que nos permite a todos reconocernos en los cambios que se están produciendo actualmente.

En la Unión Europea, el crecimiento del conocimiento con valor productivo implica asumir el triángulo del conocimiento que toma como bases del trabajo, la formación, la investigación y la innovación. Son los tres pilares del triángulo del conocimiento en la sociedad del conocimiento.
\end{abstract}

La tercera misión de la Universidad significa que esta asume institucionalmente el triángulo del conocimiento desde dos grandes objetivos: por un lado, la responsabilidad social institucional de la universidad; y, por otro, el compromiso de transformar el conocimiento en valor económico, incidiendo en la competitividad y facilitando la innovación, la creatividad y el desarrollo cultural, social, científico y tecnológico. La educación, la innovación y la investigación se relacionan en la universidad y la transferencia de conocimiento creado en la universidad se convierte en objetivo estratégico.

Ahora bien, cuando hablamos de transferencia, no estamos hablando de aplicación de mi conocimiento, sino de encontrar las vías eficaces de crear una necesidad de esa aplicación o hacer ver esa necesidad a los receptores de la red de transferencia. Eso es algo nuevo que tenemos que aprender a hacer, individualmente, en unos casos, y colectivamente, como facultad, en otros, porque la transferencia no es igual en cualquier área y disciplina. Desde la perspectiva de la Pedagogía, el dominio de la función de transferencia no se 
logra automáticamente, requiere formación, inversión y reformulación de las funciones de los profesores de universidad.

PALABRAS CLAVE: misiones de la universidad, tercera misión, transferencia de conocimiento, sociedad del conocimiento, gestión del conocimiento, crisis de universidad.

\title{
THE 'THIRD MISSION' OF THE UNIVERSITY, KNOWLEDGE TRANSFER AND KNOWLEDGE SOCIETIES. AN APPROACH FROM PEDAGOGY
}

\begin{abstract}
The notion of an information society is based on technological progress. In the knowledge society, science becomes a matter of State and knowledge is regarded from the perspective of productive development of a social, cultural and economic nature.

For UNESCO, the fact of referring to societies, in the plural, expresses the explicit intention of rejecting the uniqueness of a model that does not sufficiently take into account cultural and linguistic diversity, the only element that allows us all to recognize ourselves in the changes that are currently being made.

In the European Union, the growth of knowledge with productive value implies assuming the triangle of knowledge that takes as bases of work, education, research and innovation. They are the three pillars of the triangle of knowledge in the knowledge society.

The third mission of the University means that it institutionally assumes the triangle of knowledge from two mains objectives: on the one hand, the institutional social responsibility of the university; and, on the other hand, the commitment to become knowledge into economic value, focusing on competitiveness and facilitating innovation, creativity and cultural, social, scientific and technological development. Education, innovation and research are related in the university and the transfer of created knowledge in the university becomes a strategic objective.

However, when we talk about transfer (knowledge transfer), we are not talking about the application of my knowledge but finding effective ways to create a need for that application or to show that need to the recipients of the transfer network. This is something new that we must learn to do, individually, in some cases, and collectively, as a faculty, in others, because the knowledge transfer is not the same in any area and discipline. From the perspective of Pedagogy, the domain of the transfer function is not achieved automatically, it requires training, investment and reformulation of the functions of university professors.
\end{abstract}

KEYWORDS: Missions of the University, Third Mission, Knowledge Transfer, Knowledge Society, Knowledge Management, University Crisis.

Recibido: 05/12/2019

Aceptado: 02/03/2020 
Correspondencia: José Manuel Touriñán López. Facultad de Ciencias de la Educación, Rúa Xosé María Suárez Núñez, s/n. Campus Sur, 15782 Santiago de Compostela, A Coruña (España). Email: josemanuel.tourinan@usc.es.

\section{INTRODUCCIÓN}

En Pedagogía, al transformar la información en conocimiento y este en educación, ponemos en marcha procesos de innovación y transferencia. La transferencia es algo inherente a la educación, no solo la transmisión y la difusión. Estamos obligados a preguntarnos desde la Pedagogía por la transferencia de conocimiento. Vamos de la universidad al sector educativo, haciendo procesos. $\mathrm{Y}$ entre ellos hay procesos de transferencia de conocimiento. El potencial de transferencia de conocimiento que hay en el conocimiento de la educación, le otorga a la transferencia de conocimiento un lugar específico en educación; un lugar que, dicho sea de paso, no ha sido bien estudiado y tampoco bien gestionado. De ahí mi interés en este artículo por la relación entre sociedades del conocimiento, transferencia de conocimiento y misiones de la universidad.

La Pedagogía es un saber de perspectiva mesoaxiológica. Valorar cada medio como educativo, es lo que le corresponde a la Pedagogía y por eso la Pedagogía es el saber que necesitamos para construir ámbitos de educación, es decir, para transformar en educativo cualquier medio que utilicemos. Vamos de la información al conocimiento y del conocimiento a la educación.

Y esto no es defender posturas cognitivistas, ni pensar que la educación se resuelve en conocimiento, sino insistir en que todo lo que se hace para educar exige conocimiento de aquello que educa, es decir, que valoramos como educativo lo que utilizamos para educar: transformamos el conocimiento en educación, porque no basta con conocer áreas culturales para educar, hay que ajustarlas a criterios de significado de educar y luego realizar la intervención, lo cual implica ejecutar mediante la acción lo comprendido e interpretado, expresándolo. Nada de esto se logra sin medios y la sociedad tiene que conocer y aprovechar la utilidad del conocimiento de la educación, cuyo potencial de transferencia e innovación se ven resaltados en las sociedades del conocimiento y en las misiones de la universidad que se vinculan a la innovación.

Y dicho esto, me gustaría aclarar en la introducción de este artículo que, en el uso normal del lenguaje, se dice transferencia 'de' tecnología, transferencia 'de' resultados y sin embargo hay una cierta tendencia a decir transferencia 'del' conocimiento. Lo cierto es que hay más conocimiento del que se transfiere y, por tanto, yo usaré la preposición y no la contracción, porque realmente se transfiere algún conocimiento, no "el" conocimiento.

En este trabajo voy a abordar la transferencia de conocimiento, asumiendo la relación ente ciencia, tecnología y sociedad, así como las implicaciones que se derivan para las misiones de la universidad en las sociedades del conocimiento. 


\section{SOCIEDADES DEL CONOCIMIENTO, TRANSFERENCIA DE CONOCIMIENTO $Y$ 'TERCERA MISIÓN' DE LA UNIVERSIDAD}

En palabras de la UNESCO, la noción de sociedad de la información se basa en los progresos tecnológicos. En cambio, el concepto de sociedades del conocimiento comprende dimensiones sociales, éticas y políticas mucho más vastas. El hecho de referirse a sociedades, en plural, no se debe al azar, sino a la intención explícita de la Unesco de rechazar la unicidad de un modelo "listo para su uso" que no tenga suficientemente en cuenta la diversidad cultural y lingüística, único elemento que nos permite a todos reconocernos en los cambios que se están produciendo actualmente. Hay siempre diferentes formas de conocimiento y cultura que intervienen en la edificación de las sociedades, comprendidas aquellas muy influidas por el progreso científico y técnico moderno. No se puede admitir que la revolución de las tecnologías de la información y la comunicación nos conduzca -en virtud de un determinismo tecnológico estrecho y fatalista- a prever una forma única de sociedad posible (UNESCO, 2005, p. 17; UNESCO, 1997).

Las sociedades del conocimiento no se reducen a la sociedad de la información. El nacimiento de una sociedad mundial de la información como consecuencia de la revolución de las nuevas tecnologías no debe hacernos perder de vista que se trata sólo de un instrumento para la realización de auténticas sociedades del conocimiento. El desarrollo de las redes no puede por sí solo sentar las bases de la sociedad del conocimiento, que debe ser vertebrada sobre los pilares de la diversidad creativa, la educación permanente, la libertad de expresión, la cooperación y la solidaridad digital, tomando como bases de trabajo, la formación, la investigación y la innovación, que constituyen los tres pilares del triangulo del conocimiento que la Unión Europea ha asumido como eje del crecimiento transformado en valor productivo durante el desempeño de J. Potocnik como Comisionado para la Ciencia y la investigación en el período 20042009 (UNESCO, 2005, 2008, 2011a y 2011b; Comisión de las Comunidades Europeas, 2005a, 2005b, 2005c, 2005d y 2009; Potocnik, 2009, Bueno, 2007) (Cuadro 1).

La noción de "sociedad del conocimiento" fue utilizada por primera vez en 1969 por un Peter Drucker y para la UNESCO, no es una noción totalmente ajena a la idea de sociedad postindustrial, a la idea de sociedad del aprendizaje y a la idea aprender a ser y a la idea de sociedad educativa (Bell, 1973; Drucker, 1969; Faure, 1973; Husén,1978; Hutchins, 1969). Posteriormente, en la década de los 90 se añaden a estas ideas la de las redes de universidades emprendedoras de Clark y Gibb (Clark, 1998; Gibb, 1993), que fueron reforzadas por los trabajos pioneros de Gibbons, Ziman y Slaughter y Leslei (Gibbons y otros, 1994; Ziman, 1994; Slaughter y Leslie, 1997). De manera que el contenido básico de la idea de sociedad del conocimiento quedaba establecido al incorporarse la idea de la universidad como agente con protagonismo especial en la relación universidad-empresa-estado-sociedad civil. La ciencia se convierte en cuestión de estado y la innovación y la educación son los fermentos de la nueva forma de relación (Touriñán, 2016, UNESCO, 2005; Bueno y Casani, 2007; UNESCO, 1997 y 2011a; Comisión de las Comunidades Europeas, 2005a, 2005b, 2005c y 2009).

En las sociedades del conocimiento, la ciencia, la tecnología y la sociedad de la información con su impronta de globalización hacen que las palabras desarrollo, progreso y "occidentalización" se equiparen intencionalmente, corriendo el riesgo de generar 
propuestas de desarrollo que impongan las soluciones particulares de occidente a cualquier país en cualquiera de sus circunstancias. La cuestión clave es -como ha definido la Sociedad para el Desarrollo Internacional en su Congreso mundial celebrado en Santiago de Compostela en 1997- responder a la pregunta qué tipo de globalización queremos, porque la globalización debe ser un instrumento para reforzar el compromiso cívico a favor de las identidades culturales regionales y los desarrollos creativos (SID, 1997).

Cuadro 1. Triángulo del conocimiento en la sociedad del conocimiento

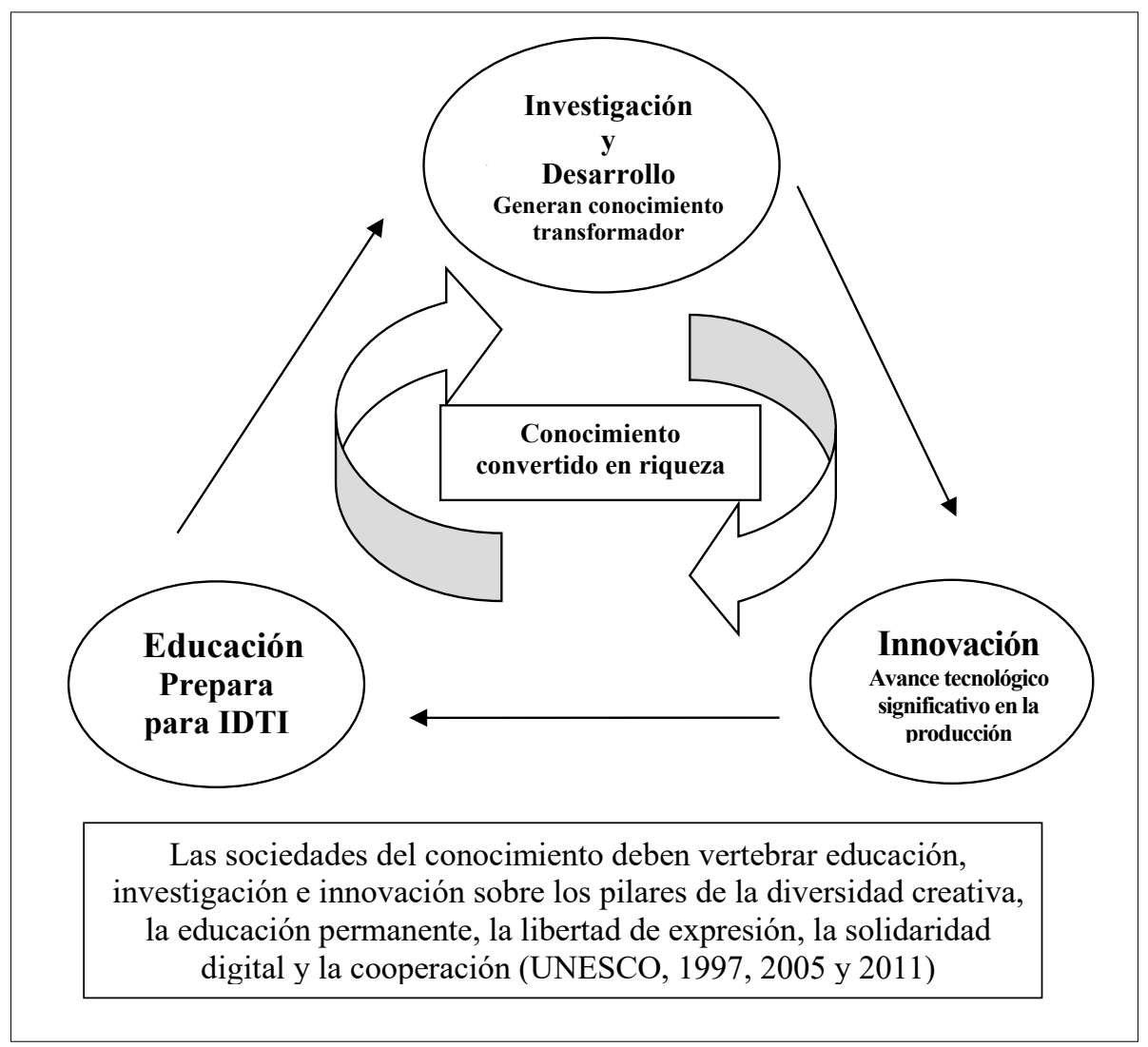

Fuente: Comisión de las Comunidades Europeas, 2005 y 2009; Potocnik, 2009; Bueno, 2007; UNESCO, 2005. Elaboración propia.

Cada vez cobra más fuerza la propuesta de defender la existencia de sociedades del conocimiento en el mundo globalizado, frente a la existencia de la sociedad del conocimiento en ese mundo, pues parece evidente que la implantación de un modelo uniforme a escala planetaria no responde a la verdadera historia de nuestros tiempos, ni al sentido de la diversidad creativa (SID, 2000; UNESCO, 1997).

Desde esta perspectiva, el factor de producción absolutamente decisivo ha dejado de ser el capital o el suelo o la mano de obra; ahora es el saber. El valor en la nueva sociedad se crea 
mediante la innovación y la productividad; ambas son aplicaciones del saber al trabajo y esa relación con el conocimiento favorece el carácter abierto de la sociedad del conocimiento.

La consideración de la falta de conocimientos como uno de los mayores problemas del desarrollo supone un tipo de discurso en el que todavía participan pocos y que, además, acostumbran a estar lejos de las esferas de influencia. Los países más desarrollados hacen énfasis en la tecnología y en el conocimiento para poder competir. Paradójicamente, en el día a día hay discursos orientados a hacernos creer que los únicos factores que influyen en la competitividad son los costes salariales y del capital, ignorándose que los conocimientos tienen un papel tan importante como esos factores. La información disponible sobre el límite a la competitividad producida por el déficit de conocimientos es abundante. Sólo a modo de ejemplo, recordemos que un estudio ya clásico del IRDAC dice que el resultado de los sistemas de enseñanza y formación (incluida especialmente la enseñanza superior), en términos tanto de cantidad como de calidad de las calificaciones a todos los niveles, es el primer determinante del nivel de productividad industrial y, por lo tanto, de competitividad de un país (Telford, 1990).

En esta industria del conocimiento, las ideas adquieren la condición de materia prima. La tendencia clásica del desarrollo tiende a apoyar una Ciencia susceptible de aplicación en el sistema productivo; las tendencias más avanzadas en el ámbito de la innovación apuntan a lo contrario: atender al diseño de un sistema productivo capaz de incorporar, en el corto plazo, los desarrollos de la investigación fundamental al ritmo que se producen en la actualidad. Y en este debate, es preciso tener muy claro que el conocimiento, la Ciencia y el propio hombre, deben afrontar la disyuntiva de incorporarse o alejarse cada vez más de los caminos que se abren al desarrollo. Obviamente, la solución, si la hay, habrá que buscarla también desde la educación y esto hace que el Sistema conocimientoeducación-innovación adquiera un significado específico en la universidad del momento: por la educación mejoramos nuestro modo de conocer y con esa mejora innovamos, descubrimos e inventamos; es decir, desarrollamos nuestros mundos y nos desarrollamos.

Descubrir, innovar e inventar son dos conceptos que dan contenido significativo al conocimiento por su relación con el desarrollo tecnológico. La evidencia de transformación de la realidad por medio de la intervención humana enfatiza el uso apropiado del conocimiento hacia la creación, la innovación y la tecnología, lo cual pone de relieve la importancia del Sistema investigación-desarrollo tecnológico-innovación (Messadié, 1999, 2000a y 2000b; Nieto, 2008). Hemos de aprender a descubrir e inventar, para conocer y transformar la realidad y nuestros contextos y eso debemos hacerlo con criterio formal de aprendizaje y con impronta de huella personal creativa. Nada de eso se consigue sin actuar intencionalmente en la educación para articular relaciones entre inteligencia, cognición, afectividad y creatividad. La tecnología y la innovación tecnológica identificada en procesos y productos que han producido una nueva impronta, una huella duradera, en la creación de conocimiento son la base del desarrollo, que no es un asunto de empresa privada simplemente o de la universidad, es una "Cuestión de Estado" y esto quiere decir que la ciencia y la educación se convierten en objeto de la política (Touriñán, 2008; Martín y otros, 1986; Hidalgo, León y Pavón, 2002).

El conjunto universidad-investigación-innovación es eje de determinación de decisiones en la política científica y en la política educativa por la implicación de la 
universidad en la formación y en la investigación. Entre la investigación y la universidad hay una unión especial que la convierte en instrumento estratégico de innovación (Touriñán, 2000a):

- La Universidad, en general, constituye una fuerza investigadora muy grande.

- Esta fuerza investigadora no tiene que disminuir, dado que hay una relación inequívoca entre calidad de la enseñanza universitaria y calidad de las actividades de investigación y desarrollo tecnológico (IDT) en las instituciones de enseñanza superior.

- La enseñanza superior puede contribuir de manera significativa al desarrollo regional, tanto por su virtualidad formativa en la investigación, como por su capacidad de innovación tecnológica. La presencia de la enseñanza superior en una región representa una inversión hacia el futuro; proporciona mano de obra altamente cualificada y constituye una fuente de conocimiento, asesoramiento e investigación utilizable por la empresa y la industria.

Esta relación entre investigación y comunidad universitaria es importante para el sistema ciencia-tecnología-sociedad y mediatizadora del desarrollo tecnológico, de tal manera que buena parte de su éxito en el desarrollo regional depende de que se alcance un nivel de comprensión general de la ciencia y de la tecnología en la sociedad, suficiente para servir de base a la difusión rápida y generalizada de las innovaciones y de la nueva tecnología.

Y en este marco de dependencia, la relación entre la empresa y la enseñanza superior es significativa para el conjunto universidad-investigación-empresa:

- Las instituciones de la enseñanza superior deberían considerar la cooperación con la industria como una parte fundamental de su misión, estando a favor de la adaptación de sus estructuras para poder realizar la colaboración.

- Las empresas deberían formular, ante sus órganos representativos, políticas positivas para fomentar la colaboración.

- Las Administraciones tienen que adoptar políticas de incentivos que estimulen la inversión de las empresas en la formación, en la investigación, y en el desarrollo.

Todas estas condiciones confirman el énfasis en el desarrollo de la sociedad del conocimiento y la importancia de reparar en los ejes estratégicos, relacionados con la educación, que afectan a la innovación (Cuadro 2):

- Sistema ciencia-tecnología-sociedad

- Sistema investigación-desarrollo tecnológico-innovación:

- Conjunto universidad-investigación-empresa

- Conjunto universidad-investigación-innovación

- Sistema conocimiento-educación-innovación, que está vinculado a los procesos de cambio y a la escuela. 
Cuadro 2. Sociedad-Estado-Ciencia-Educación-Innovación-Transferencia en las sociedades del conocimiento

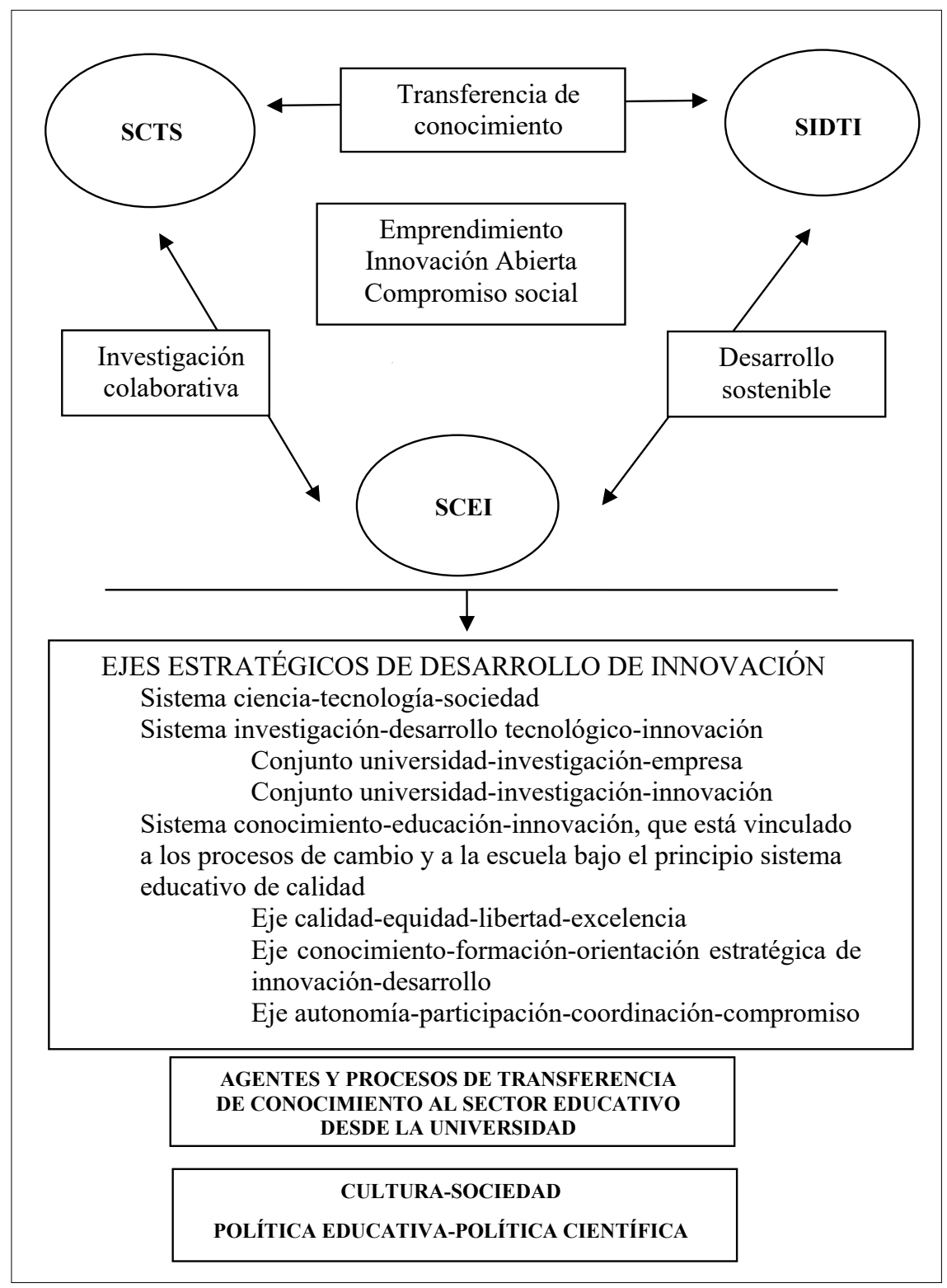

Fuente: Touriñán, 2016. Elaboración propia.

La Unión europea se planteó esta nueva relación universidad y sociedad en el Libro blanco de la educación y de la formación (Comisión de las Comunidades Europeas, 1995a) y en 2003 se incorpora abiertamente a la idea de la nueva universidad 
innovadora y emprendedora bajo el lema "Construir la Europa del Conocimiento" y se concretó en la metáfora del "triángulo del conocimiento" en Europa que hace especial énfasis en el papel de la educación en cualquiera de los niveles de enseñanza con el objeto de armonizar educación, innovación e investigación y desarrollo tecnológico (Touriñán y Sáez, 2015; Comisión de las Comunidades Europeas, 2004a, 2004b, 2005d y 2003; Bueno, 2007).

El conocimiento e innovación se hacen motores para un crecimiento sostenible potenciados desde la educación desde 2003 y se concreta progresivamente en la Estrategia Europa 2020, cuyo objetivo es garantizar que la recuperación económica de la Unión Europea (UE) después de la crisis económica y financiera reciba el apoyo de una serie de reformas para construir unas bases sólidas para el crecimiento y la creación de ocupación en la UE hasta 2020. Al mismo tiempo que hace frente a las debilidades estructurales de la economía y los asuntos económicos y sociales de la UE, la estrategia también tiene en cuenta los desafíos a más largo plazo que suponen la globalización, la presión sobre los recursos y el envejecimiento. Es la Europa del conocimiento y el crecimiento inteligente, sostenible e integrador. La Estrategia Europa 2020 debe permitir a la UE alcanzar un crecimiento (Comisión de las Comunidades Europeas, 2010 y 2011):

- inteligente, a través del desarrollo de los conocimientos y de la innovación;

- sostenible, basado en una economía más verde, más eficaz en la gestión de los recursos y más competitiva;

- integrador, orientado a reforzar el empleo, la cohesión social y territorial.

El triángulo del conocimiento y la relación entre los sistemas ciencia-tecnologíasociedad, conocimiento-educación-innovación e investigación-desarrollo tecnológicoinnovación son el fundamento de una voluntad manifiesta de hacer crecer, asumiendo que la universidad es motor del desarrollo productivo'. La Universidad se focaliza hacia la 'tercera misión', al lado de la docencia y la investigación. La tercera misión se basa en dos grandes objetivos: por un lado, la responsabilidad social institucional de la universidad y, por otro, el compromiso de transformar el conocimiento en valor económico, incidiendo en la competitividad y facilitando la innovación, la creatividad

1. Se puede hacer un seguimiento del desarrollo continuado en España consultando, además, los textos siguientes:

Comisión de las Comunidades Europeas (2013). La enseñanza superior europea en el mundo. Comunicación de la Comisión al Parlamento Europeo, al Consejo, al Comité Económico y Social Europeo y al Comité de las Regiones. COMISIÓN EUROPEA. Bruselas, 11.7.2013, COM(2013) 499 final. http://ec.europa. eu/transparency/regdoc/rep/1/2013/ES/1-2013-499-ES-F1-1.Pdf (Recuperado 22.3.2019 en la web).

ME (2011). Estrategia universidad 2015. Contribución de las universidades al progreso socioeconómico español. Octubre, 2010. Madrid: Secretaría General de Universidades (Recuperado el 22.3.2019) http:// www.mecd.gob.es/docroot/universidad2015/flash/eu2015-flash/document.pdf

MECyD (2014). Estrategia para la internacionalización de las universidades españolas 2015-2020. Resumen Ejecutivo. Madrid: Ministerio de Educación, Cultura y Deporte. Recuperado el 22.3.2019 en la página web del Ministeiro http://www.educacionyfp.gob.es/educacion-mecd/dms/mecd/educacion-mecd/areas-educacion/universidades/politica-internacional/estrategia-internacionalizacion/ResumenEjecutivo-Final/ResumenEjecutivo.Final.pdf

MECyD (2016). Estrategia para la Internacionalización de las Universidades Españolas 2015-2020. Madrid: Ministerio de Educación, Cultura y Deporte. Recuperado el 22.3.2019 en la página web del Ministeiro https://sede.educacion.gob.es/publiventa/descarga.action?f_codigo_agc=18182 
y el desarrollo cultural, social, científico y tecnológico (CRUE, 2018; Vilalta, 2013 y 2016; Touriñán, 2000b; Touriñán y Bravo, 2000; Tourinán y Sáez, 2015; Matía, 2015). La tercera misión, apunta a Innovación Abierta, Emprendimiento, Cooperación social, Desarrollo sostenible, Transferencia de conocimiento y Formación (Cuadro 3).

Pretender reducir la tercera misión a un problema de valor económico del conocimiento, obviando la función de responsabilidad social de la universidad y su implicación en el desarrollo cultural y social, cercenando la misión tradicional de la universidad de desarrollo social y cultural, productivo y crítico, es no entender que los modelos integrados referidos al modo de producción del conocimiento han evolucionado desde la hélice de triple pala a modelos de cuatro y cinco palas que siempre han venido a reforzar, como veremos en el epígrafe siguiente, la idea de que ningún modelo es puro y que el modelo es el que debe ajustarse a la realidad y no al revés, de tal manera que la relación entre innovación, emprendimiento y cooperación social es integral en los modelos avanzados con red responsable de la transferencia y la sociedad civil no es un apéndice en esa relación (Carayannis y Campbell, 2010 y 2009; Arias y Aristizábal, 2011; Bayona y González, 2010; Bueno y Casani, 2007; González, 2009; Molero, 2008; Martínez, 2008; Rodríguez, 2017; Velasco, Zamanillo y Intxaurburu, 2007).

Cuadro 3. Tercera misión de la universidad

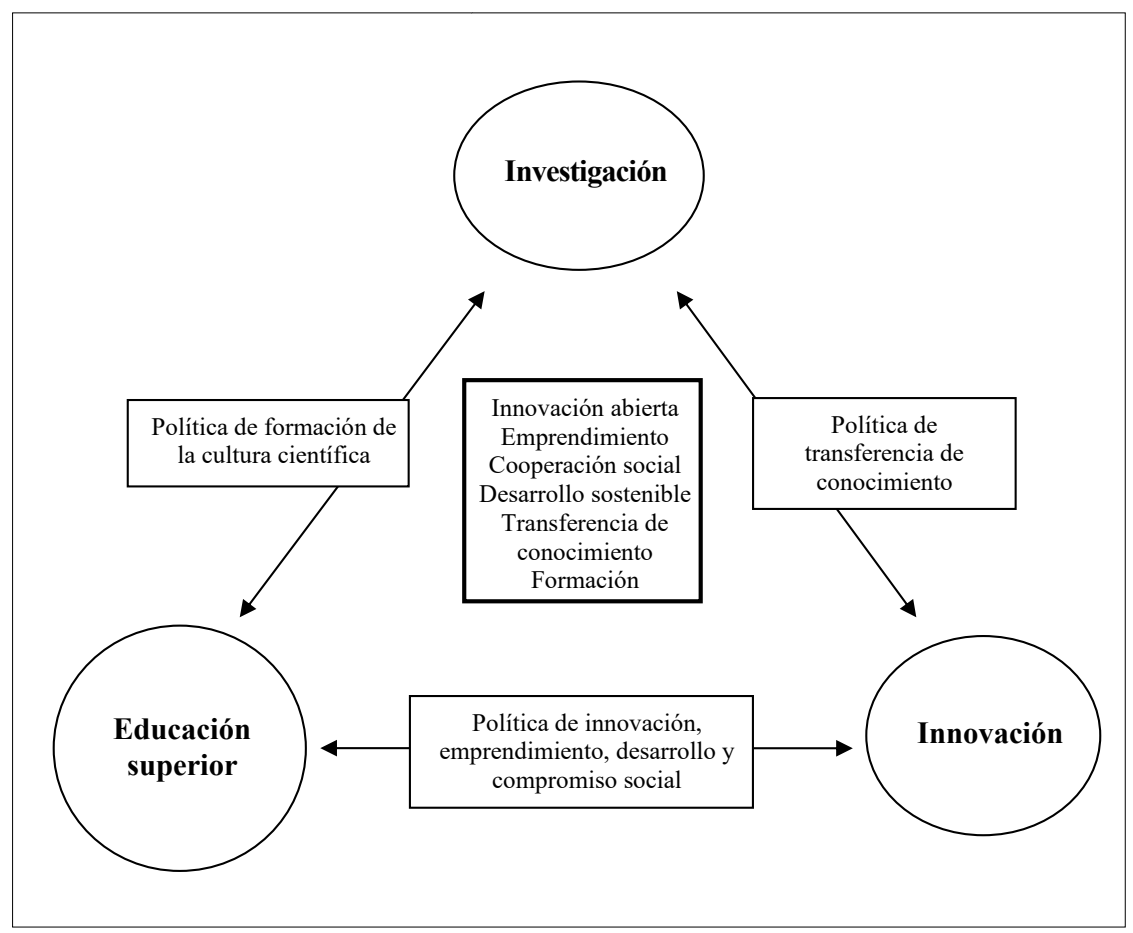

Fuente: Potocnik, 2009; Bueno, 2007; Touriñán, 2016; CRUE, 2018; Vilalta, 2013. Elaboración propia. 
En las sociedades del conocimiento, la tercera misión de la universidad reclama para la transferencia de conocimiento la orientación hacia la innovación, el desarroIlo social, cultural, emprendedor y cooperativo, bajo un esquema integrador de la relación entre los sistemas CTS-IDTI-CEI. Y de este modo, en el modelo de transferencia están unidos emprendimiento cultura, sociedad, cooperación y sostenibilidad, asumiendo las posiciones generales de la Unión Europea sobre innovación y desarrollo. Y esa relación integrada, como acabamos de ver en este epígrafe, responde además a las posiciones asumidas por la UNESCO y la Unión Europea, respecto de las sociedades del conocimiento desde los sistemas ciencia-tecnología-sociedad, conocimiento-educación-innovación, investigación-desarrollo tecnológico-innovación. Y dicho esto, también conviene resaltar que, reducir la figura de lo cultural, lo social y lo cooperacional a un transversal respecto del emprendimiento, en la tercera misión de la universidad y en la transferencia de conocimiento y su singularidad en cada caso, es hacerle un flaco favor a esos términos, porque lo mismo podría aplicarse a la ciencia, la investigación y el emprendimiento y considerarlas transversales respecto de la cultura y la cooperación. Lo cierto es que todas tienen que ser funciones igualmente importantes en la tercera misión y todas son transversales o todas son singulares en relación con el desarrollo y la innovación, pero ninguna queda subalternada a las otras en cuanto a su condición fundamentante en la definición de la universidad actualmente $^{2}$. Como veremos con más detalle en el epígrafe siguiente, las misiones de la universidad ya existen y son todas igualmente fundamentales para la definición de universidad (Conesa, 2019; Rodríguez, 2017; Broncano, 2019; Vidal, 2018, Touriñán, 1996a, 1996b, 1997a, 1997b, 2000a y 2000b; SI(e)TE, 2018; Pulido, 2009).

\section{EL MODELO DE TRANSFERENCIA DE CONOCIMIENTO TIENE QUE ESTAR ORIENTADO EN RED A LA INNOVACIÓN PRODUCTIVA, CULTURAL Y SOCIAL}

De acuerdo con Arias y Aristizábal, podemos decir que, con el advenimiento de la sociedad del conocimiento y la economía de bienestar (Bell, 1973; Drucker, 1993), la manera tradicional de producción de conocimiento científico y tecnológico de las universidades y centros de investigación, denominada Modo 1 ó Ciencia 1, ha sufrido una serie de transformaciones que han propiciado la configuración y el tránsito

2. No es el momento de hacer análisis del concepto, en la nueva situación, pero sí procede contextualizar el paso de las preocupaciones centradas en la autonomía universitaria a las preocupaciones centradas en la convergencia en el Espacio Europeo de Educación Superior (EEES; http://www.eees.es/), que es un desarrollo singular, centrado en la docencia, en la homogeneización de los estudios y en la movilidad internacional de estudiantes, pero distinto del que corresponde a la transferencia de conocimiento, al triangulo del conocimiento y a la tercera misión de la universidad.

La Declaración de Bolonia del mes de junio de 1999, recoge las consideraciones y compromisos respecto del sistema universitario europeo declarados y firmados por 30 Ministros o Secretarios de Estado de universidades para la creación del Espacio Europeo de Educación Superior (http://www.eees.es/pdf/Declaracion_Bolonia.pdf). Este documento asume en lo esencial el contenido de la Magna Charta Universitarum firmada un año antes en la Sorbona (http://www.magna-charta.org). La evolución de los Tratados Constitutivos de la comunidad europea, desde el primero de ellos, Tratado de París, firmado en 1951, puede consultarse en la página "Los Tratados y el parlamento europeo" http://www.europarl.europa.eu/about-parliament/es/in-thepast/the-parliament-and-the-treaties. Además, la particular evolución de los tratados firmados para consolidar el avance del EEES puede verse en http://www.eees.es/es/eees-desarrollo-cronologico. 
hacia el Modo 2 ó Ciencia 2 (Gibbons et al., 1994; Gibbons, 1998; Nowotny et al., 2001; Gómez Sal, 2016; Bayona y González, 2010)

En el Modo 1, los problemas se plantean y solucionan dando atención principalmente a unos intereses académicos de una comunidad específica; mientras que, en el 2, el conocimiento se produce a la luz de un contexto de aplicación, es decir, buscando ser útil bien sea a la sociedad, al Estado o a las empresas. Se pasa de una concepción disciplinar a una concepción transdisciplinar y el conocimiento ya no queda vinculado solo a la Universidad encerrada en sí misma. La universidad, cada vez más, busca la función de servicio, no solo al conocimiento, sino también al desarrollo económico, cultural y social, productivo y crítico.

La mirada dirigida desde la universidad hacia el desarrollo económico productivo hace que la transferencia de conocimiento pueda ser considerada, a su vez, de acuerdo con esos dos modos de producir conocimiento científico y tecnológico, de tres modos: no comercial, comercial y de creación de nuevas empresas (Upstill y Symington, 2002; Pirnay, Surlemont y Nlemvo, 2003; Bueno, 2007; Etzkowitz y Leydesdorff, 1995; Bozeman, 2000; Carayannis y Campbell, 2012):

- El Modo 1 (no comercial) se refiere, básicamente, a la difusión del conocimiento sin ningún tipo de interés comercial y contratos entre los emisores y receptores; se lleva a cabo en escenarios académicos mediante publicaciones, seminarios, ponencias, diplomados, cursos de extensión;

- El Modo 2 (comercial), la transferencia parte de un acuerdo comercial entre la universidad y su contraparte, bien sea el Estado o la industria, y se realiza por medio de consultorías, capacitaciones, investigación conjunta y comercialización de licencias o patentes de productos desarrollados durante la investigación;

- El Modo 3 (creación de nuevas empresas) implica la creación de las Spin-off universitarias, empresas dedicadas a la explotación del conocimiento, tecnología o resultados de investigación desarrollados dentro de las universidades.

En esta misma línea se expresan diversos autores, apuntando al sentir general y común de que la transferencia, se haga mediante el mecanismo de divulgación y difusión o se haga orientada a resolver problemas sociales, responde básicamente a tres grandes modelos (Hidalgo, León y Pavón, 2002; Arias y Aristizábal, 2011; Velasco, Zamanillo y Intxaurburu, 2007; Molero, 2008; Bekkers y Bodas, 2008):

- Modelo lineal, en el cual la transferencia está precedida de los descubrimientos científicos y de la consecución de patentes. En el modelo lineal están implicados la universidad, el científico o centro de investigación, la oficina de transferencia de resultados de investigación (OTRI) y las empresas.

- Modelo dinámico, que mejora el modelo lineal y tiene como propósito la transferencia de conocimiento por medio de la comercialización o difusión

- Modelo integrado, que ha evolucionado, desde el protagonismo del Estado en las relaciones entre las empresas y el Estado, a una interacción entre el Estado, la empresa y la universidad con campos de acción delimitados para cada uno; 
para llegar a su versión última, en la que cada uno de los actores asume las funciones propias y las de todos, de tal manera que las universidades crean empresas y éstas, a su vez, crean centros de investigación.

También hay una coincidencia generalizada respecto al hecho de que la transferencia de conocimiento no es lineal; es, preferentemente, en redes, cuyo flujo vital es el conocimiento creado y transferido. Diferentes agentes y organizaciones intercambian información y conocimiento para producir innovaciones en el marco de relaciones de cooperación y redes a nivel territorial local, regional, nacional o internacional.

Por consiguiente, el contenido básico del modelo integrado quedaba establecido al considerar a la universidad como co-protagonista del desarrollo productivo en una imagen de hélice de triple aspa (mal llamado modelo de 'triple hélice', por una mala traducción del texto inglés, que dice expresamente "hélice triple": administración, universidad y empresa (Etkowitz y Leydesdorff, 1997). Al modelo de Hélice triple le corresponden fundamentalmente tres objetivos:

- Dirigir el proceso de transferencia de conocimiento tecnocientífico hacia la generación de innovación.

- Promover la creación de la cultura científica y de innovación que necesita la sociedad actual.

- Formar a los asesores y gestores tecno-científicos o en I+D como agentes inductores de innovación (Cuadro 4).

Cuadro 4. Transferencia de conocimiento hélice triple

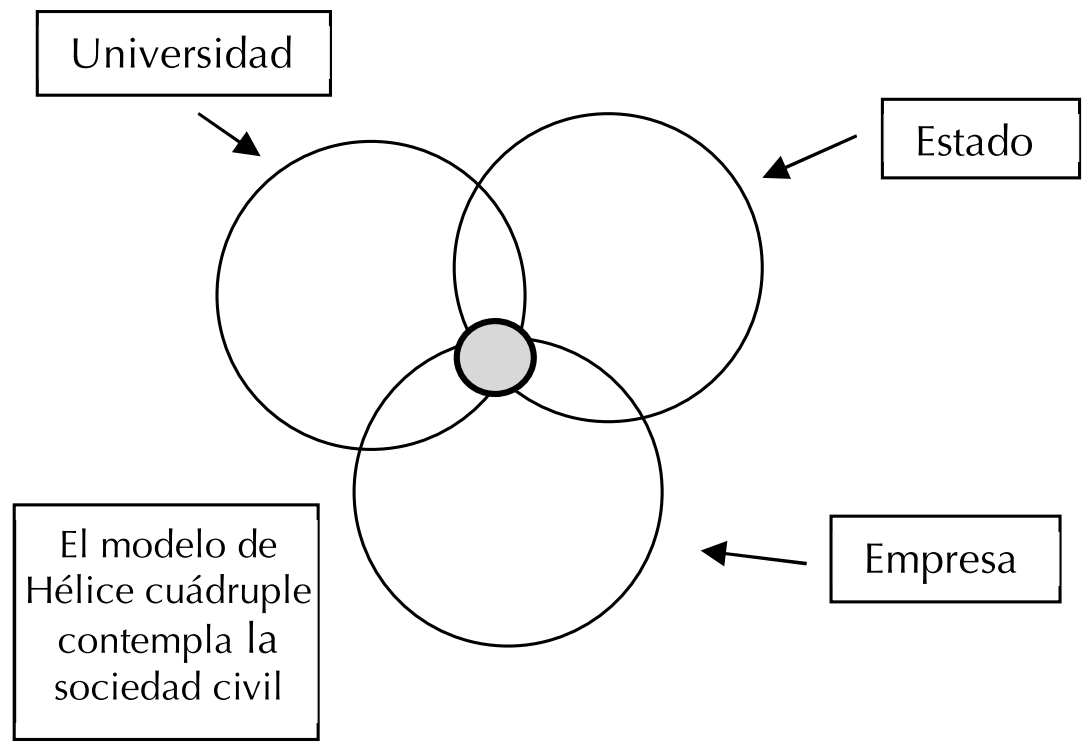

Fuente: Touriñán, 2016. Adaptado de Etzkowitz y Leydesdorff, 1997. 
En cualquier caso, después de años de aplicación del modelo integrado de Hélice de tres aspas, parece poder afirmarse que este, si bien explica una buena parte de mecanismos de relación entre universidad y empresa e investigación, no es un buen ejemplo para convertirse en modelo social, porque no se conjuga bien con el papel de la sociedad civil y las innovaciones derivadas de realidades culturales y educativas que forman parte de la sociedad y que también contribuyen al desarrollo, igual que la empresa, la universidad y la administración pública.

Según Teresa González, puede afirmarse, con fundamento en investigación, que el modelo de hélice de triple aspa (González, 2009):

- Selecciona sólo una pequeña parte del panorama total de la investigación;

- Estiliza las condiciones y los sucesos reales para producir una imagen de un espacio de agencia abstracto (intersticial);

- Exagera la comunalidad y el consenso entre los distintos actores y partes implicadas, al tiempo que atenúa la diferenciación y el conflicto de intereses que surge de la especificidad sistémica de las partes intervinientes.

Desde finales de la primera década de este milenio, se ha incorporado a la literatura especializada el modelo en red de hélice cuádruple (de cuatro aspas), que agrega un cuarto componente al marco de interacciones entre la universidad, la industria y el gobierno: la sociedad civil y los medios de comunicación de masas de la sociedad digital. El objetivo es cerrar las brechas entre la innovación y la sociedad civil. De hecho, este marco afirma que bajo el modelo de hélice de triple aspa, las tecnologías emergentes no siempre coinciden con las demandas y necesidades de la sociedad, lo que limita su impacto potencial. Este nuevo marco tetrádico enfatiza la responsabilidad social de las universidades, además de su papel de docencia e investigación. El modelo en red de cuádruple aspa es el es que la Unión Europea se propone adoptar para el desarrollo de una sociedad competitiva basada en el conocimiento (Carayannis y Campbell, 2009 y 2010). El paso de una lógica tríadica a una lógica tetrádica, que involucra a universidad, empresa, administración pública y comunidad-sociedad civil, en un mundo digital y globalizado, parece indicar que la universidad refuerza su papel de motor del desarrollo tecnológico y de responsabilidad en el desarrollo económico, social y cultural, productivo y crítico: además de docencia e investigación, hay una tercera misión de la universidad que la define como motor del desarrollo tecnológico y una cuarta misión que la orienta al desarrollo social productivo y crítico, desdoblando la misión clásica de desarrollo social y cultural productivo y crítico, cuya pujanza está relegando a otro plano las misiones clásicas de estudio y profesión (CRUE, 2018; Bueno, 2007; Vilalta, 2013). Además de la docencia, el estudio, la investigación y la profesión, esta nueva prioridad caracteriza a la universidad en la innovación, el emprendimiento y la cooperación social (Touriñán, 2016):

- La universidad tiene un papel fundamental para propiciar y generar innovación en el Sistema de I+D+I, actuando como agente y espacio dinamizador de estos procesos de innovación. 
- La Universidad, tiene un papel fundamental como agente de emprendimiento, a través de la puesta en práctica de procesos de transferencia de conocimiento.

- La universidad tiene una función de compromiso con el crecimiento y el desarrollo sostenible de la comunidad social en la que se integra y es facilitadora de una mayor cooperación social en los procesos de $\mathrm{I}+\mathrm{D}+\mathrm{I}$ en la sociedad y economía del conocimiento.

Atendiendo a la definición recogida por la Comisión Europea en el 'Libro Verde de la Innovación', la innovación es la transformación de una idea en un producto o un servicio comercializable nuevo o mejorado, un procedimiento de fabricación o distribución operativo, nuevo o mejorado, o un nuevo método de proporcionar un servicio social. Es, por lo tanto, por definición, una tarea, un resultado y un proceso. A veces mejoramos los equipos o las funciones de los equipos que intervienen en la innovación (innovación de organización). A veces, la innovación se refiere a cambios en el objeto producido (innovaciones de productos). A veces, se mejora el proceso de producción de bienes o de prestación de servicios (innovaciones de proceso) (Comisión de las Comunidades Europeas, 1995b).

A pesar de la existencia de numerosos modelos que han tratado de explicar lo que constituye el proceso de innovación, la mayoría de ellos resultan incapaces de capturar toda la complejidad de la realidad que trata de describir. A medida que se han producido avances en el entendimiento del proceso de innovación, han ido surgiendo nuevos modelos cada vez más sofisticados. En la actualidad, los modelos coexisten en sus diferentes formas (Velasco, Zamanillo y Intxaurburu, 2007; Padmore, Schuetze y Gibson, 1998).

La Comisión Europea estableció la existencia de diversos modelos de innovación (Comisión Europea, 1995, 2004 y 2011):

- Innovación derivada de la ciencia (de su empuje, Technology Push)

- Innovación derivada de las necesidades del mercado (Market Pull)

- Innovación derivada de los vínculos entre los actores en los mercados

- Innovación derivada de redes tecnológicas

- Innovación derivada de redes sociales.

Lo que persiguen los modelos es que, por medio de la transferencia de conocimiento, la innovación llegue a la empresa y a la sociedad. Hay innovación de proceso, de producto y de organización y para todo ello se puede transferir conocimiento (Fernández, 2000). La innovación no es un simple cambio, la innovación exige referencia a necesidades sociales, culturales o empresariales para las cuales el cambio implícito en la innovación supone una mejora o satisfacción de la necesidad y puede basarse en una nueva tecnología, como es el caso de la innovación vinculada a las TICs y puede incluso conllevar un cambio de mentalidad. Si esto es así, la transferencia de conocimiento debe atender 
prioritariamente a los desarrollos productivos, sean sociales, culturales o económicos, pues, en términos de emprendimiento y transferencia es tan importante pensar en una empresa al uso como pensar en una ciudad educadora, en una ciudad creativa o en una ciudad amigable con los mayores, que son áreas de interés de la educación y, por consiguiente, de la Pedagogía (Touriñán, 2017; SI(e)TE, 2012; Claxton, 2001; Sebastián, 2008; Herrera, Bonilla y Molina, 2013; https://es.unesco.org/creative-cities/content/ciudades-creativas; Asociación Internacional de Ciudades Educadoras; OMS, 2007, https://www.who.int/ageing/ age_friendly_cities_guide/es/).

Finalmente hay que defender que la innovación tiene lugar en la empresa, pero el conocimiento en la que se sustenta puede provenir de muy diversas fuentes: interna a la empresa (inhouse); proveedores; las empresas iguales (peers) (competidoras o no); clientes10 y sector público (transfiere conocimiento a través de institutos técnicos o laboratorios de investigación, la celebración de diversos eventos como conferencias, a través de agencias reguladoras, etcétera.

El Modelo integrado insiste en la importancia del aprendizaje que tiene lugar dentro y entre las empresas y sugiere que la innovación es, fundamentalmente y de manera genérica, un proceso distribuido en red en el que la sociedad civil tiene su lugar (Cuadro 5).

Cuadro 5. Modelo en red para gestión de innovación

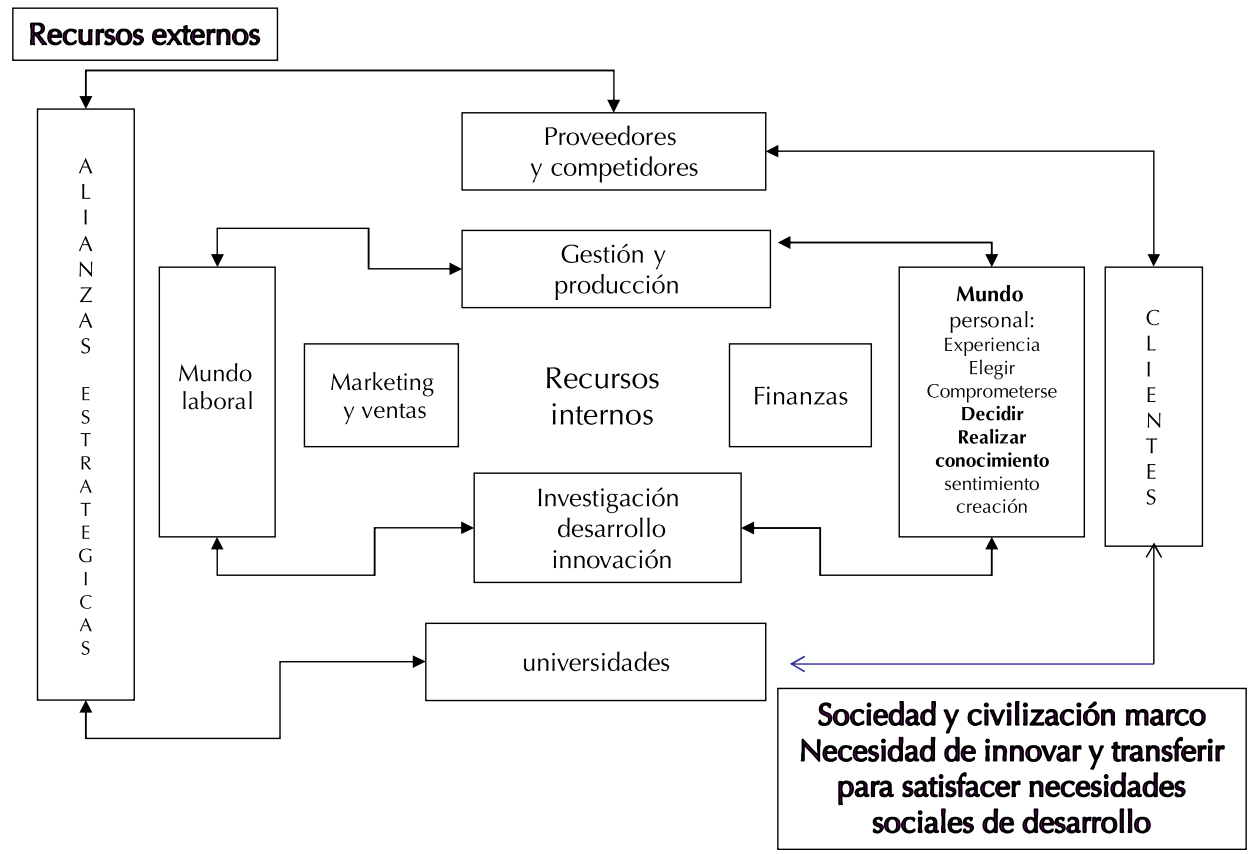

Fuente: Trott, 1998. Elaboración propia. 
El modelo en red permite entender que el incremento de conocimiento se consigue fundamentalmente mediante la ejecución de actividades de I+D, pero eso no impide entender que hay otras modalidades de aprendizaje como son el aprendizaje por la práctica ("learning by doing"), que se logra con la realización de las actividades de producción; el aprendizaje por el uso ("learning by using"), que se extrae de estudiar la forma en que los clientes emplean los productos de la empresa; el aprendizaje por el error ("learnig by failing"), proveniente del análisis de las decisiones erróneas adoptadas. Estos lemas de educación se aplican en la formación continua desde el aprendizaje-servicio que es una buena mezcla de todos ellos muy útil en pedagogía laboral, pedagogía gerontológica, en pedagogía ambiental, en pedagogía social y en cooperación al desarrollo (https:// aprendizajeservicio.net/que-es-el-aps/). Este flujo de formación continua se hace de manera que los nuevos conocimientos se acumulen a los conocimientos previamente existentes y de este modo se incrementa la convicción de que las empresas que triunfarán en el futuro serán aquellas que consigan descubrir cómo lograr el compromiso de su gente y que desarrollen una capacidad de aprender a todos los niveles de la organización (Velasco, Zamanillo y Intxaurburu, 2007; Vilalta, 2013; UNESCO, 2005).

Gestionar el proceso de innovación en red supone en sí mismo un aprendizaje considerable, incluyendo el aprendizaje organizacional, y éste, no estará exento de costos, tanto en términos de tiempo, como de inversión en equipos y formación. Es un conocimiento especializado que hay que hacer si se quiere conseguir efectividad en la transferencia de conocimiento desde los centros de formación y desde cada trabajo de investigación en la universidad (MartínezGómez, 2017). Sin embargo, los beneficios potenciales a largo plazo son considerables: eficiencia y manejo de información en tiempo real a través de todo el sistema de innovación, mayor conocimiento mutuo entre los agentes, potenciación de la investigación colaborativa; difusión social del trabajo universitario; implicación productiva en la sociedad, etcétera (López, Blanco y Guerra, 2009).

En mi opinión la complejidad del proceso es tal que hay que empezar a hablar realmente de la transferencia y no solo como desiderátum. Y, por tanto, hay que asumir que el cambio innovador se puede referir a: una idea, un material, una práctica, un contenido, una metodología, un patrón cultural, una relación entre las personas o instancias que participan en el hecho educativo, una forma de aplicar una norma, un procedimiento administrativo, un artefacto organizacional, una técnica transferible a una empresa o centro educativo, una buena práctica o una creencia o un valor y un largo etcétera que solo se acaba con las posibilidades de la creatividad de los agentes. Ahora bien, para que el cambio surta efecto debe ser asumido e interiorizado en el plano personal, y, debe ser institucionalizado en el plano de la organización receptora; no es una tarea sencilla ni simple; es una tarea específica y especializada que responde a una necesidad social sentida. Y cuando hablamos de actividad específica, con fundamento en conocimiento especializado que sirve para satisfacer una necesidad social reconocida estamos hablando de 'profesiones'. La gestión del conocimiento es una tarea profesional que utiliza como instrumento el conocimiento creado por 
los investigadores. Que sea vista esa tarea como una función más de la profesión de profesor universitario que implica por el momento funciones de docencia, investigación, gestión administrativa y representación institucional, es algo que no se puede establecer sin más. No hay coste cero en esta atribución y tampoco es de recibo desde el punto de vista de la competencia a utilizar que se habilite una forma de evaluar la transferencia de conocimiento y que no se haya habilitado antes un programa de formación de profesores, para el logro de las competencias se requieren para hacer la transferencia. No es lo mismo, y es un error grosero de consecuencias injustas para el mérito y la competencia, no distinguir entre conocimientos transferibles, creados por los profesores de universidad en el ejercicio de sus funciones profesionales, y transferencia de conocimiento, que es una tarea especializada, distinta de la crear conocimiento (Touriñán, 2018; Luque, 2018; Astigarraga, 2019; Fraser y Dunstan, 2010).

Conocer, enseñar, investigar, gestionar académicamente, y representarse a sí mismo y a los demás en la comunidad universitaria y crear conocimiento, son funciones acrisoladas de los profesores de universidad. Incluso cabe admitir que la difusión del conocimiento en revistas, congresos, simposios, prensa escrita y mundo digital son formas de transferencia que van asociadas al conocimiento creado. Y también va asociado al conocimiento su aplicación. Pero, cuando hablamos de transferencia, no estamos hablando de aplicación de mi conocimiento, sino de encontrar las vías eficaces de crear una necesidad de esa aplicación o hacer ver esa necesidad a los receptores de la red de transferencia. Eso es algo nuevo que tenemos que aprender a hacer, individualmente, en unos casos, y colectivamente como facultad, en otros, porque la transferencia no es igual en cualquier área y disciplina. No debemos ignorar que, desde la perspectiva de la transferencia de conocimiento, la cultura de la innovación no es un fin en sí misma, es un medio para satisfacer una necesidad social desde el conocimiento creado y, por tanto, cada institución tiene que identificar los valores éticos y sociales que sostienen su propia cultura de la innovación y a qué desarrollos empresariales, sociales y culturales productivos se orienta la transferencia y todo ello sin dejar de ver que la diferencia entre intereses individuales y de la organización en cuanto a la transferencia son un problema de poder (Touriñán, 2016, Martínez, 2008; Bermejo, 2018, Ramos, 2019; García, 2019; Luque, 2018; Astigarraga, 2019; Fraser y Dunstan, 2010; Díaz-Barriga, 2010).

El volumen de conocimiento que ya se ha producido en torno a la gestión del conocimiento y su transferencia, podemos afirmar que no cabe ninguna duda de su carácter especializado y específico. La planificación de la transferencia de conocimiento creado ya permite distinguir ocho fases, que no necesariamente se siguen en el orden previamente especificado; más bien conforman un ciclo que se reinicia para continuar avanzando a modo de espiral en ciclos derivados de mejora permanente (Ortega, Ramírez, Torres, López, Servín, Suárez y Ruiz, 2007, p. 167) (Cuadro 6). 
Cuadro 6. Fases de planificación de la transferencia

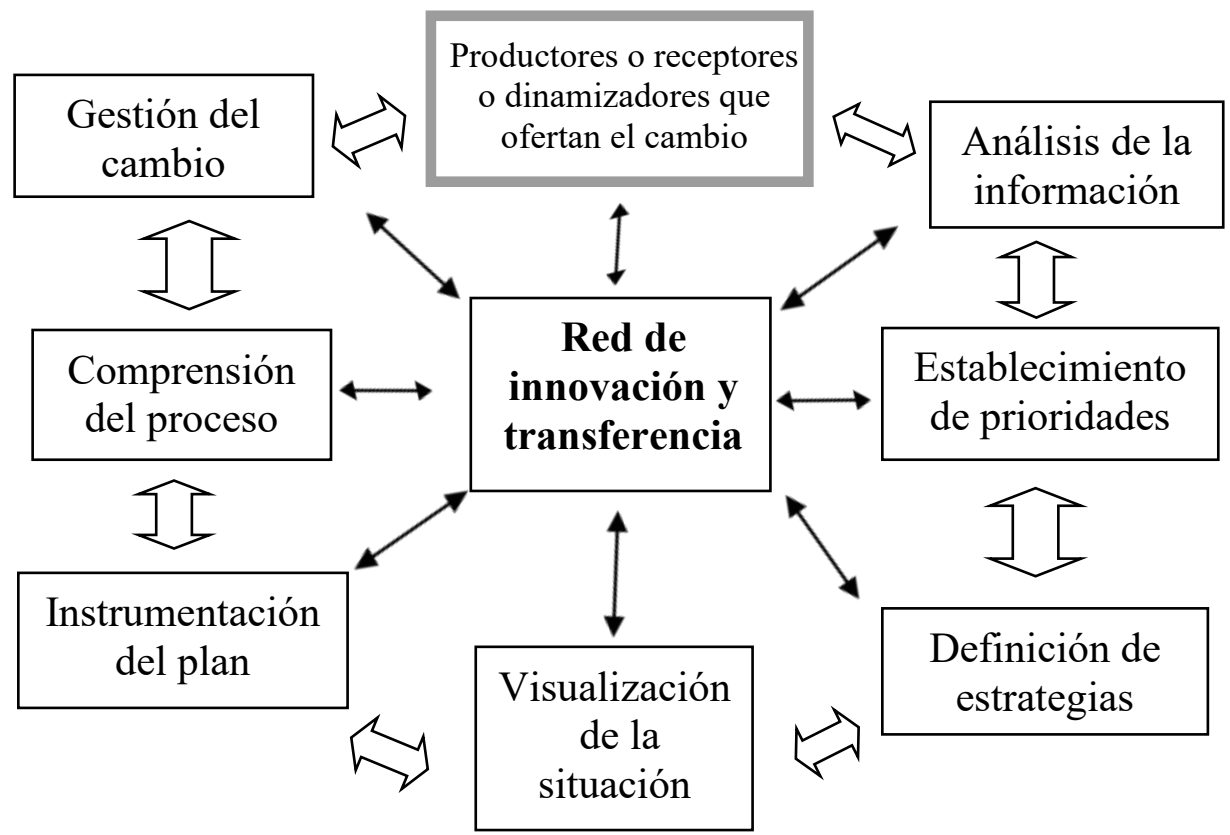

Fuente: Ortega, Ramírez, Torres, López, Servín, Suárez y Ruiz, 2007, p. 160. Elaboración y adaptación propia.

\section{CRISIS DE LA UNIVERSIDAD, EXTENSIÓN UNIVERSITARIA E INNOVACIÓN. ORIENTACIÓN INSTITUCIONAL DE LOS RECURSOS DE INVESTIGACIÓN Y POSICIONAMIENTOS ESTRATÉGICOS DE LAS UNIVERSIDADES}

En el año 1973 Spackman se preguntaba en un artículo incisivo si eran necesarias las escuelas (Spackman, 1973). Su contenido sigue siendo actual; su argumento de fondo era que las escuelas no habían sido capaces de cumplir su cometido y cada vez era más evidente la duda acerca de la conveniencia de conservar la escuela tal y como era en aquel momento, porque desde una determinada óptica era posible enfrentar el aprendizaje real con la escuela (que era obligatoria, orientada a títulos, con planes de estudios poco flexibles, con agrupación de niños por edades, con organización jerárquica y con desprecio a las nuevas redes educativas).

Volver a pensar en la misión y papel de la institución escolar dentro de la sociedad que constituye su entorno, nacional e internacional, es una práctica constante en todas las épocas. La perspectiva histórica permite afirmar que la crisis persistente en que vive la institución escolar no es una crisis de la escuela como institución, sino la crisis o la decadencia de un determinado modo de hacer escuela. En el fondo, como antes apuntamos, es un problema de creación de nuevos usos (SI(e)TE, 2013). 
Con relación a la educación, solemos hablar con mucha frecuencia y sin control del significado de 'revolución'. La revolución educativa y la revolución escolar son dos expresiones cuyo dimensionamiento está hipervalorado por su interés mediático. Aun así, el profesor Torres ha delimitado doce grandes transformaciones, que identifica como revoluciones en el inicio del siglo XXI y que hay que tenerlas en cuenta, porque afectan a las áreas del currículum y a sus contenidos (Torres, 2011, p. 15).

Valga como ejemplo de lo anterior la idea revolucionaria de 'Tercer Entorno' (la sociedad-red) que, junto con el entorno rural y el entorno ciudad, configura nuevas posibilidades para la sociedad, también se ha usado como connotación específica de un cambio revolucionario o de un cambio que preconiza el advenimiento de una nueva etapa de civilización (Echeverría, 1999; Castells, 2001; Neira, 2011). Este cambio ha sido analizado ya desde muy diversas perspectivas: como Tercera Comunicación (la audiovisual-virtual, frente a la gestual y verbal), como Tercera Revolución (la del lenguaje de hipertexto-multimedia-digital, frente a la del lenguaje oral y escrito), como Tercer Espacio (el de la pantalla interactiva -la interficie-, frente al del encerado de la escuela y al del libro). Este nuevo "Entorno" genera condiciones icónicas y simbólicas singulares que afectan al lenguaje, la comunicación y la forma de vida (OCDE, 2003). Todo ello contribuye a reforzar la idea de que la revolución en nuestros días implica cambio tecnológico y que la nueva civilización implica cambio de mentalidad (Touriñán, 2014).

Por su parte, el profesor Esteve, en dos de sus últimos libros, nos habla de la tercera revolución educativa como la revolución que corresponde a la educación en la sociedad del conocimiento (Esteve, 2010a y 2010b): una revolución que debe generar auténtica educación inclusiva y exige reconvertir nuestros sistemas de enseñanza en sistemas educativos (Esteve, 2010a, pp. 72, 134 y 150) y transformar nuestras instituciones escolares en centros de educación (Esteve, 2010b, pp. 87 y 103).

Es mi opinión que el sistema educativo ya está definido en las leyes como un sistema para educar, que debe cumplir finalidades educativas, y la escuela es una institución educadora cuyo objetivo es el logro de las finalidades de la educación en cada etapa. Por definición el sistema educativo y la institución escolar están concebidos para educar y la legislación ampara y promueve la legítima acción educativa de los centros escolares en el sistema educativo. Más que revolución, es reforma; hay que corregir abusos y generar nuevos usos (SI(e)TE, 2013).

Es mi opinión fundada en el conocimiento de la educación que es posible diferenciar aptitudes para conocer la educación (relacionadas con dominio de la teoría, la tecnología y la práctica propias de la educación como conocimiento y actividad), las aptitudes para investigar (relacionadas más directamente con el dominio de la metodología y la capacidad de verificación y prueba), las aptitudes para la enseñanza (más unidas al dominio del conocimiento de la educación específico de los métodos de enseñanza y su aplicación, un conocimiento que requiere el dominio suficiente de los contenidos del área en la que se va a enseñar), y las aptitudes para intervenir educativamente en un área de experiencia (que se identifica además con las competencias vinculadas a la realización del carácter y del sentido de la educación entendida como tarea o como resultado) (Touriñán, 2015). 
La confusión entre estas competencias es, en buena parte, la causa de que los sistemas educativos enseñen y no eduquen y que los sistemas escolares no cumplan con su función primordial que es educar utilizando las áreas culturales para generar experiencia axiológica de valor educativo. Para educar con un área cultural, la condición de experto o la identidad de la competencia viene dada por diversas actividades (Touriñán, 2016):

- Conocimiento de la educación (teórico, tecnológico y práctico) al nivel suficiente para realizar la función

- Conocimiento (teórico, tecnológico y práctico) del área de experiencia, en la que va a educar, al nivel suficiente para realizar la función

- Dominio de las destrezas para ejercer técnicamente la función

- Competencia práctica de la intervención como especialista

$\mathrm{Ni}$ es verdad que el profesor de un área de experiencia cultural es un aprendiz de esa área que enseña, ni es verdad que necesariamente el que más conoce área de experiencia es el que mejor la enseña, ni es verdad que el que mejor domine una destreza es el que mejor enseña a otro a dominarla, a menos que, tautológicamente, digamos que la destreza que domina es la de enseñar esa destreza.

El especialista en educación realiza una actividad específica con fundamento en el conocimiento especializado que le permite la formalización académica de la expresión y la experiencia cultural más allá de la experiencia personal de la práctica de una actividad cultural, con objeto de lograr con cada educando formación, general o profesional, desde un área cultural, en un nivel determinado, dentro del sistema educativo.

'Crisis' no es un término unívoco. Tiene diversos significados y según se entienda, así se puede discurrir para encontrar soluciones. La palabra crisis debe reservarse en educación para aquellas situaciones en que una institución o sistema es incapaz de cumplir sus fines o de dar respuesta a los nuevos fines que caigan dentro su ámbito de responsabilidad, hasta el punto de que ello implica una pérdida de legitimidad y se aboca a una reestructuración, a su desaparición o a una sustitución por otra alternativa.

Cuando la educación está en crisis, hay necesariamente crisis de valores, porque en ese caso, en la educación, o no se sabe para qué sirve, o no se dispone de los medios para responder a las expectativas nuevas.

Atendiendo al conocimiento de la educación, carece de sentido pensar que resolver "una" crisis es encontrar los valores que acaben con "la" posibilidad de crisis. La crisis es parte estructural de la educación, porque la educación siempre tiene que innovar y adaptarse a nuevas situaciones. Lo que procede es entender el sentido relacional de los valores y el carácter temporal de los fines y medios en cada orientación formativa temporal; una orientación en la que diversas instituciones tienen responsabilidad compartida. 
En el lenguaje común, 'crisis' significa momento de cambios decisivos en cualquier proceso o situación que origina inestabilidad e incertidumbre sobre el desarrollo posterior. En este sentido se habla de crisis de gobierno, crisis educativa, crisis axiológica, crisis económica, etc. Por extensión, 'crisis' significa dificultad, problema o mala situación (Coombs, 1978). Pero también se entiende que crisis es el momento de manifestación aguda de algún síntoma o problema después del cual se produce un claro empeoramiento o una mejoría. En este sentido, decimos que un paciente enfermo entró y está en estado crítico, que la economía entra en crisis o que la educación está en crisis.

Desde la perspectiva del conocimiento de la educación, podemos distinguir dos expresiones que hacen referencia a cuestiones distintas respecto de la crisis. Se habla de "crisis DE la educación", cuando nos referimos a que la educación ha perdido su orientación; la crisis de la educación hace referencia a la pregunta "Educación, ¿para qué?"; 'crisis de la educación' quiere decir que no se sabe cuáles son las finalidades de la educación. Pero, además, se habla de "crisis EN la educación", cuando queremos significar que lo que estamos haciendo en educación no sirve para los fines que le son propios; la crisis en la educación hace referencia a la pregunta "qué medios estamos utilizando para educar"; 'crisis en la educación' quiere decir que cuestionamos el uso y distribución de medios aplicados a la educación.

Es posible analizar por separado la crisis de finalidades y la crisis de medios en relación con la educación. Pero en ambos casos hemos de ser conscientes de que estamos ante dos situaciones que de hecho nos obligan a reconocer que la educación está en crisis. Hay crisis DE la educación, hay crisis EN la educación y ambos casos son casos de la educación en crisis. Se entiende, por tanto, que la consulta a la literatura especializada nos permita establecer, respecto de la educación en crisis, dos grandes bloques de problemas: los que afectan a las finalidades, que se identifican genéricamente como problemas vinculados a la función de la educación y los que afectan a los medios, que se identifican como problemas vinculados a la oportunidad y la organización (SI(e)TE, 2014a).

Los problemas relativos a la educación en crisis se vinculan siempre a razonamientos sobre la legitimidad de la educación, ya sea esta legitimación de las ideas o legitimación de los medios y de las formas de llevar adelante los cambios en medios y fines: no es lo mismo el programa educativo que pone por delante la libertad o la equidad; no es lo mismo hacer una reforma educativa a coste cero que aportar los recursos económicos que se requieren lograr con eficacia y eficiencia los fines propuestos; no es lo mismo proponer una reforma sin modificar los recurso humanos y técnicos que asumir el compromiso de lograr las finalidades con recursos humanos y técnicos adecuados a la nueva orientación; no es lo mismo imponer un cambio que acordar un cambio (Wirt y Harman, 1987). Todas estas diferencias tienen que ver con la educación en crisis y hacen necesario el discurso sobre la legitimación y la legitimidad de las ideas, de los medios y de las formas.

$\mathrm{Y}$ todo esto se hace siempre en un marco territorial legalmente delimitado y reconocido como tal internacionalmente. En el contexto territorial, las acciones importantes para la vida y el bienestar de los sistemas nacionales pueden extenderse más allá de nuestras fronteras locales. Puede haber efectos internacionales de cambios 
nacionales: es el caso de un invento en un país o de una forma de atajar un problema en un país que es exportable internacionalmente. Puede haber conjuntos de acontecimientos multiterritoriales que generan cambios en muy diversos países: es el caso de las guerras y de las recesiones económicas. La solución a estos acontecimientos en cada país no tiene que ser la misma, pero siempre exige entender la relación justicapoder-verdad, porque las legitimaciones, ética, política y técnica deben tener su lugar propio en la intervención (Touriñán, 2017).

Forma parte de la educación la idea de reforma y conviene dejar claro que la reforma en la educación no puede reducirse a la corrección de abusos, ni siquiera consiste principalmente en eso; la reforma es siempre creación de nuevos usos (Ortega y Gasset, 1968a y 1968b). Volver a pensar en la misión y papel de la educación y de las instituciones que la llevan a cabo dentro de la sociedad que constituye su entorno, nacional e internacional, es una práctica constante en todas las épocas. La perspectiva histórica permite afirmar que la crisis persistente en que vive la educación no significa desaparición de la educación, ni de su función, sino la crisis o la decadencia de un determinado modo de hacer y de cumplir su significado en la orientación formativa temporal correspondiente. Precisamente por eso la solución es una cuestión de corrección de abusos y de creación de nuevos usos, pero no se acaba; la crisis es parte estructural de la educación que siempre ha de construir orientaciones formativas temporales en cada territorio.

Se trata de entender que, en el marco del desarrollo humano, el reto es hacer frente a la responsabilidad compartida individual y corporativamente, sin renunciar a las competencias de cada una de las instituciones implicadas. Ni los padres son los profesionales de la educación, ni la escuela tiene que suplantar o sustituir la función de la familia, ni el educando debe dejar de ser agente de su educación. Sociedad civil, familia, Estado y escuela afrontan el reto de la formación, no sólo como una cuestión de hecho, sino como un compromiso de voluntades hacia lo que es valioso en la educación.

Afirmo, por consiguiente, que, en la propuesta de procedimiento formulada en el párrafo anterior, la familia, la escuela, el Estado y la sociedad civil son agentes que integran y desarrollan la educación y afirmo, además, que, ahora, la sociedad civil puede reforzar a la familia y a la escuela de un modo singular y distinto al del estado para fortalecer el papel de los padres en la educación de los hijos.

Lo que procede, en la sociedad abierta y pluralista, es que el Estado desarrolle el sistema educativo y delimite su competencia en educación. Pero, al mismo tiempo, es obligado que el Estado propicie y garantice el ejercicio de las funciones propias de la sociedad civil, los padres y la escuela en la formación (SI(e)TE, 2016).

La tesis clave es distinguir claramente, a fin de salir bien parados de la polémica, los límites entre la prestación de un servicio público y la pública intromisión en el derecho del individuo a marcarse sus propios objetivos.

La solución en la educación no está en elegir en lugar del educando su modo de vida, sino en elegir aquellos modos de intervención pedagógica que garantizan la capacitación del educando para elegir y realizar su proyecto de vida, aprendiendo a construir y usar experiencia para responder a las exigencias de su desarrollo en cada situación, de acuerdo con las oportunidades (Touriñán, 2015). 
La formación, para ser efectiva, tiene que ser asumida con libertad, innovación y compromiso (Huberman, 1973). Libertad, porque hay que garantizar pedagógicamente en la orientación formativa la condición de agentes libres con derechos y libertades a educandos y educadores; innovación, porque hay que afrontar educativamente con nuevas propuestas los retos de la diversidad en la sociedad actual en relación con la orientación formativa temporal adecuada; compromiso, porque la intervención tiene que especificarse y cualificarse de acuerdo con lo que estamos dispuestos a asumir del significado de educación en cada orientación formativa.

Parece pues que la contraposición entre fines de educación y diversidad de expectativas sociales dirigidas al sistema educativo se resuelve en la misma medida que distingamos el lugar de la decisión técnica y el de la decisión política, respecto de las finalidades. Podemos distinguir finalidades que tienen su origen en el conocimiento de la educación y finalidades que tienen su origen en las expectativas sociales. Hay metas pedagógicas y hay metas educativas nacidas de expectativas sociales dirigidas al sistema educativo. Las expectativas dirigidas al sistema forman parte de la orientación formativa temporal siempre que se ajusten a las condiciones de legalidad y legitimidad que le son propias y no tergiversen la relación entre decisión técnica, decisión moral y decisión política. En ese sentido, la sociedad es factor de desarrollo educativo, pero al mismo tiempo la educación es factor de desarrollo social y la educación atiende no solo a criterio social, sino a criterios de significado que legitiman la decisión técnica (Touriñán, 2015).

Hoy sabemos que transformamos conocimiento en educación para transformar la sociedad, mejorar la educación y seguir educando al hombre; precisamente por eso hacemos el sistema educativo que hacemos, lo legitimamos y decidimos la orientación formativa temporal para la condición humana. No hay una respuesta única a la educación en crisis que sea válida en cualquier territorio. Unas veces se requieren cambios en los fines y otras veces en los medios, o en ambos. Unas veces son cambios de proceso, otras de producto y, en respuestas más perdurables, se requieren modificaciones de estructura organizativa. Unas veces, la educación apuntará a cambios vinculados al eje calidadequidad-libertad-excelencia, otras veces, apuntará al eje conocimiento-educación-innovación-desarrollo y en otras ocasiones, apuntará al eje compromiso-autonomía-participación-coordinación, porque cada situación es distinta.

La orientación formativa temporal está elaborada a partir de la singularidad de las situaciones, del conocimiento de la educación generado, del avance de las áreas culturales y de la pertinencia y relevancia de los valores vigentes dentro de una determinada sociedad. Las materias escolares se agrupan en la arquitectura curricular, atendiendo a los niveles del sistema educativo, respetando los criterios y rasgos de definición nominal y real de educación y, desde áreas culturales consolidadas y transformadas en ámbitos de educación, la orientación formativa temporal para la condición humana, oferta el patrón, modelo educativo en cada sociedad concreta, en el marco de identidad, diversidad y territorialidad (Touriñán, 2017).

No hay una propuesta definitiva territorial, siempre es axiológicamente relacional y debe conjugar el valor educativo y la vinculación pertinente a las expectativas que la sociedad dirige al sistema para afrontar la adversidad en tiempos de crisis y capa- 
citar al educando para actuar educadamente en cualquier momento. Y, hoy en día, la relación entre política, justicia y verdad, pensando en el conjunto sociedad-poderlegitimación, exige prestar atención no solo a la decisión política, sino también a la decisión técnica que fundamenta la verdad del contenido de la ley y a la acción propia de la sociedad civil que es agente moral con especificidad propia para velar por la justicia y el progreso social (Arendt, 1996; SI(e)TE, 2014b).

Y dicho esto, afirmo que hablar de Tercera misión de la universidad, bien por reflejo de otras terceras revoluciones o misiones que he referido al principio de este epígrafe, o bien por la implicación de la universidad en la idea de cambio tecnológico, innovación y emprendimiento, como si esa tarea no estuviera ya considerada en la misión clásica de la universidad en el siglo XX de desarrollo social, cultural y cooperativo, productivo y crítico, es no entender el papel de la extensión universitaria en el Siglo XX.

La 'tercera misión' de la universidad, tal como ahora se viene definiendo, no es una misión nueva, sino la consecuencia de la misión de desarrollo económico, social y cultural, productivo y crítico, que se le exige a la universidad desde el siglo XX, asumiendo el triángulo del conocimiento en las sociedades del conocimiento y su focalización hacia la innovación abierta, la ciencia abierta, la investigación colaborativa, el emprendimiento y la cooperación. Esta misión no debe cuestionar ni relegar en importancia las misiones de estudio y profesión, que forman parte de nuestra universidad. Pero todo parece indicar que estas dos son colocadas en orden de preferencia posterior respecto de docencia, investigación y transferencia, sin que los criterios de prioridad y ordenación se hayan explicitado previamente en su significado.

En España, por ley, los departamentos universitarios son unidades de investigación y docencia. Las facultades son unidades de organización vinculadas al estudio, en los planes, y a las competencias profesionales que se logran, en la carrera. Y eso no debe obviarse al plantear con visos de realidad la transferencia de conocimiento integrada en la tercera misión. Si se relega el estudio y la profesión como misiones de la universidad (en nuestro país el título académico habilita para el ejercicio profesional, de acuerdo con las disposiciones vigentes), la 'tercera misión' es una mala formulación.

Priorizar no debe significar minimizar la importancia de las otras misiones. Sustantivamente, todas las misiones de la universidad son igualmente importantes; la pérdida o minusvaloración de cualquiera de ellas produce un daño estructural en la identidad de la institución universitaria. Y eso es lo que parece que está ocurriendo, porque los partidarios de la denominación 'tercera misión' ya apuntan a una 'cuarta misión' subsecuente de evaluación de retornos y del impacto y alcance de los resultados (CRUE, 2018). Es mi opinión que las misiones de la universidad ya existen y son todas igualmente fundamentales para la definición de universidad. 'Tercera' solo puede tener sentido adjetivo, no sustantivo. $Y$ si desde la 'tercera' ya se infiere una futura 'cuarta misión' orientada a evaluación de retornos y centrada, según la CRUE, en el impacto y en el alcance de los resultados que la investigación universitaria genera en la sociedad, en todos los ámbitos del conocimiento y en la actividad universitaria en general, eso no debe significar ni dar lugar a que solo la docencia y la investigación son más importantes que la tercera misión y que el estudio y la profesión pasan a estar por detrás de la cuarta futura misión. 
Es mi opinión que 'evaluar' no es una cuarta misión; es una parte del proceso de planificación y así debería de considerarse para no mermar la categoría de las misiones de la universidad. Las mal usadas, a veces, denominaciones 'tercera' y 'cuarta' misión son prioridades y funciones de la universidad, pero no misiones de la universidad propiamente dichas, sino parte y consecuencia de una misión fundamental de la universidad: el desarrollo productivo y crítico, que se manifiesta en innovación para el desarrollo emprendedor, cultural, social y de cooperación. Y esta gran misión está en igualdad de condiciones, con la docencia, la investigación, el estudio y la profesión, respecto de la estructura identitaria de la universidad. Debemos distinguir misiones y tareas derivadas y funciones propias de profesores, teniendo muy claro que priorizar misiones no significa anular misiones o convertir funciones necesarias para realizar una misión en una nueva misión.

En las Universidades se habla hoy, igual que hace 50 años (ya casi estamos en el cincuentenario de la revolución de mayo del 68), de crisis de número de alumnos, de crisis financiera, de crisis de adecuación de planes de estudios, incluso de crisis de nuevas prioridades universitarias. Pero ya comienza a asumirse que, en el fondo de todas estas crisis puntuales, subyace una crisis más profunda y global: es la crisis de gestión en la que los responsables de la administración universitaria a nivel estatal, a nivel autonómico y a nivel de centros tenemos que definir nuestras posiciones, pues, si hay un ámbito de responsabilidad compartido, también hay un conjunto de exigencias diferenciadas.

Y dado que hablamos de exigencias y, eso sí, dando por sentada la distinción, necesaria e internacionalmente aceptada, entre educación superior y educación universitaria (Porta y Lladonosa, 1998; Solá, 2002), reitero mi alusión a Ortega y Gasset para destacar con él que la reforma universitaria no puede reducirse a la corrección de abusos, ni siquiera consiste principalmente en eso; la reforma es siempre creación de nuevos usos (Ortega, 1968a).

Esta idea está presente en la obra de muy diversos pensadores que escriben sobre la Universidad. La Universidad es docencia, es cultura, es profesionalización, es estudio, es investigación y es desarrollo social, cultural, cooperativo, emprendedor, crítico e innovador. Es cierto que, cuando se estudia el concepto de Universidad, la definición ya no puede hacerse en relación sólo al sentido que "universitas" tenía en la Edad Media; tampoco puede hacerse por aproximación al concepto griego de "academia", porque hoy la Universidad es potenciadora de la movilidad social, del desarrollo personal, de la promoción social y del desarrollo científico-tecnológico; potencia ciertas esperanzas colectivas y es, por lo tanto, un servicio de incuestionable valor que, en la misma medida en que se dio el paso de la llamada "sociedad de la información" a la sociedad del conocimiento, incrementó su valor como institución de inversión en capital humano (Touriñán, 2014; Fontela, 2001; Pérez Díaz y Rodríguez, 2002).

Volver a pensar en la misión y papel de la Universidad dentro de la sociedad que constituye su entorno, nacional e internacional, fue una práctica constante en todas las épocas. La perspectiva histórica permite afirmar que la crisis persistente en que vive la Universidad desde hace unas décadas no es una crisis de la Universidad como institución, sino la crisis o la decadencia de un determinado modo de hacer univer- 
sidad. En el fondo, como antes apuntamos, es un problema de creación de nuevos usos (Touriñán, 1997a).

Es posible que en esta vorágine de desarrollo universitario tengamos que reconocer que en el lugar de "universidad", tendremos la "multiversidad", no sólo por la variedad de las actividades académicas, o por la importancia cada vez mayor de los cursos de verano, sino también por su modo de integrarse en el entorno social circundante y por la heterogeneidad de su clientela (Touriñán, 1996b; Salorio, 1993; Almarcha, 2001).

También es verdad que el espacio y los recursos universitarios, ahora, nos obligan a hablar de universidades orientadas a polos de excelencia que optimicen los recursos industriales, materiales y humanos de la zona donde está ubicado el campus (Touriñán, 2000a y 2000b).

Es seguro, asimismo, que, en los nuevos modelos universitarios, las exigencias de espacio y de clima adecuado para la masa crítica investigadora nos llevará a hablar de un modo particular de macrocentros integrados que cobijan muy diversas titulaciones, agrupadas bajo el principio de complementariedad interdisciplinar para grandes áreas científicas, en campus de excelencia e innovación acordes con los perfiles estratégicos decididos en cada universidad (Touriñán, 1997b).

Pero, en cualquier caso, no tenemos que olvidar que todo eso es la consecuencia última de una búsqueda constante para definir y construir estructuras organizativas y de gestión que garanticen de forma eficaz la realización de los valores sustantivos de la institución universitaria: la docencia, la investigación, la cultura, el estudio, la profesionalización y el desarrollo productivo: social, cultural, cooperativo, emprendedor, crítico e innovador (Touriñán, 1997a y 2016).

La orientación estratégica ayuda a definir el perfil de la universidad. Ambos, orientación y perfil, son elementos a considerar en la financiación y en la racionalización política del sistema. Los modelos, partiendo de la alternativa genérico-exclusividad y, de acuerdo con variables explícitas, permite identificar perfiles de universidad orientados según el caso hacia:

- Captación o no de alumnado de otras universidades.

- Incremento o no de títulos de demanda universitaria.

- Generalización o especialización del perfil.

- Orientación a la docencia o más a la investigación.

- Creación de conocimiento y promoción empresarial

A las Universidades, con el perfil definido dentro del sistema, les corresponde, con libertad académica y autonomía institucional la realización de sus funciones, mejorando la pertinencia, la diversidad y la calidad de la institución en el marco del sistema, bajo la forma de facultades, institutos, centros de liderazgo o campus de excelencia (http://www.educacion.gob.es/eu2015).

En este marco, la universidad está en condiciones de atender muy diversas tareas que determinan la posibilidad de elaboración de sus planes estratégicos de desarrollo 
(Touriñán, 2000a; Alburquerque, 2008).

- diagnósticar y analizar sus necesidades y su potencial;

- desarrollar el marco estratégico planificado en el que deberían integrar investigación, tecnología, innovación y políticas relacionadas;

- poner en práctica programas y acciones que incorporen prioridades y medidas específicas apropiadas para ser ejecutadas en relación con sus posicionamientos estratégicos;

- fomentar la promoción de la propia comunidad científica y la definición de su perfil en el advenimiento de la sociedad de la información y del conocimiento;

- asumir su compromiso con el desarrollo regional, coordinándose con las instituciones de su territorio;

- aportar fondos para financiar sus actuaciones y propuestas.

La comunicación institucional y la extensión universitaria alcanzan, de este modo, valor estratégico en el desarrollo universitario, que, en su adaptación a las nuevas constantes del mundo actual, tiene que hacer frente a nuevas exigencias (Almarcha, 2002; Solá, 2002):

- Creación de relación duradera con los educandos, clientes y usuarios para atraer, retener-fidelizar y mantenerla

- Generar el valor de la marca que corresponde con la calidad percibida de la institución desde su perfil (prestigio, excelencia y reputación que configuran su imagen social)

- Fortalecer el sistema de gestión del conocimiento en la institución, con objeto de ofertar y producir contenidos de calidad

- Establecer mecanismos para integrar la cultura emprendedora en la universidad

- Desarrollar su organización y servicios de apoyo en redes tecnológicas capaces de potenciar su transferencia con el entorno

Las redes de comunicación se constituyen como soporte físico de las redes tecnoeconómicas, tecno-educativas y tecno-académicas de gestión que ya están determinando un contexto coherente de trabajo y de progreso en el ámbito de la universidad y de la educación superior, identificada como bien público y comercio de servicios (García Guadilla, 2004; Berbegal, 2017; Barro, 2019; Salaburu, 2017; Haug y otros, 2018).

Desde esta perspectiva de aproximación, la cooperación se entiende como acción individual y de grupo y como acción orientada a la innovación, el desarrollo, el crecimiento del conocimiento y la proyección internacional del trabajo realizado o realizable, que, se quiera o no, debe de ir marcando las líneas de extensión de la universidad hacia opciones coherentes que apuntan hacia nuevos clientes y usuarios, 
nuevas áreas de influencia, nuevas relaciones emprendedoras, nuevas vías de internacionalización y transferencia de resultados, nuevas formas de desarrollo curricular ajustados a la innovación y a la producción y gestión del conocimiento.

La ciencia, la tecnología y la sociedad de la información con su impronta de globalización hacen que las palabras desarrollo, progreso y "occidentalización" se equiparen intencionalmente, corriendo el riesgo de generar propuestas de desarrollo que impongan las soluciones particulares de occidente a cualquier país en cualquiera de sus circunstancias. La cuestión clave es -como ha definido la Sociedad para el Desarrollo Internacional en su Congreso mundial celebrado en Santiago de Compostela en 1997- qué tipo de globalización queremos, porque la globalización debe ser un instrumento para reforzar el compromiso cívico a favor de las identidades culturales regionales y los desarrollos creativos (SID, 1997).

Cada vez cobra más fuerza la propuesta de defender la existencia de sociedades del conocimiento en el mundo globalizado, frente a la existencia de la sociedad del conocimiento en ese mundo, pues parece evidente que la implantación de un modelo uniforme a escala planetaria no responde a la verdadera historia de nuestros tiempos, ni al sentido de la diversidad creativa (SID, 2000; UNESCO, 1997).

Desde esta perspectiva, el factor de producción absolutamente decisivo ha dejado de ser el capital o el suelo o la mano de obra; ahora es el saber. El valor en la nueva sociedad se crea mediante la innovación y la productividad; ambas son aplicaciones del saber al trabajo y esa relación con el conocimiento favorece el carácter abierto de la sociedad del conocimiento, que queda plasmado en las relaciones educacióninnovación-investigación-desarrollo que he delimitado en el epígrafe anterior. Y, así las cosas, en mi opinión, la relación entre sociedades del conocimiento, transferencia de conocimiento y misiones de la universidad deben ser contempladas dese la óptica de la innovación, pero también desde la óptica de la extensión de la universidad, su perfil decidido y su orientación estratégica.

\section{CONSIDERACIONES finAles, A MODO DE CONCLUSIONES}

En mi opinión, no solo hay conocimientos transferibles; hay transferencia como actividad específica y especializada. Yo no soy especialista en transferir y aunque he hecho difusión del conocimiento que he producido y transferencia de conocimiento como he sabido, siempre he sentido la necesidad de que alguien haga de mediador difusor y gestionador del conocimiento que yo he creado. La utilidad de mi trabajo se vería mucho mejor rentabilizada. Las empresas educativas no están próximas a la academia, ni conocen el uso de lo que se hace en la universidad. Y tampoco saben a dónde acudir, porque los centros en los que estamos trabajando no tienen reconocida su actividad de transferencia y los organismos mediadores se ocupan en otras facetas de la transferencia.

Crear conocimiento, no es transferirlo, y saber crearlo, no es saber transferirlo. Son competencias distintas, con independencia de que haya algunas actividades de transferencia que pueden ser realizadas por un profesor sin especial dominio técnico del proceso de transferencia de conocimiento. 
Conocer, enseñar, investigar, gestionar académicamente y representarse a sí mismo y a los demás en la comunidad universitaria, y crear conocimiento son funciones acrisoladas de los profesores de universidad. Incluso cabe admitir que la difusión del conocimiento en revistas, congresos, simposios, prensa escrita y mundo digital son formas de transferencia que van asociadas al conocimiento creado. Y también va asociado al conocimiento su aplicación.

Pero, cuando hablamos de transferencia, no estamos hablando de aplicación de mi conocimiento, sino de encontrar las vías eficaces de crear una necesidad de esa aplicación o hacer ver esa necesidad a los receptores de la red de transferencia. Eso es algo nuevo que tenemos que aprender a hacer, individualmente, en unos casos, y colectivamente, como facultad, en otros, porque la transferencia no es igual en cualquier área y disciplina. Necesitamos que las facultades tengan competencia y personal especializado en transferencia de conocimiento, con objeto de dar respuesta adecuada a la difusión, aplicación y penetración de nuestro conocimiento creado en los grupos receptores. No estaría de más, en esta misma línea de aproximación de la transferencia de conocimiento a los centros de producción del mismo (facultades, OPIs, investigadores y grupos de investigación), contar en el caso de educación con el ICE (Instituto de ciencias de la educación) para potenciar el valor de servicio ofertable y de desarrollo económico, social, cultural y productivo del conocimiento pedagógico: su función es de asesoría e informes, además de generar investigación como los de los institutos; pero por su peculiar dependencia orgánica de la universidad: la elaboración de informes sobre el sistema educativo, la formación y desarrollo de formación pedagógica del profesorado de secundaria (en el futuro, MIR de profesores) y la transferencia de conocimiento relativa a educación encontrarían en este organismo una plataforma idónea, distinta y complementaria a la vez, del papel propio de las facultades de ciencias de la educación y de los profesores en esta tarea.

Conviene no olvidar, en concordancia con lo dicho a lo largo de este texto, que el volumen de conocimiento que ya se ha producido en torno a la gestión del conocimiento y su transferencia, permite afirmar que no cabe ninguna duda respecto del carácter especializado y específico de tal tarea.

En el imaginario colectivo de los profesores de universidad, los profesores crean el conocimiento que va a ser transferido por los agentes de la transferencia. $Y$ el proceso de la transferencia implica, además del conocimiento creado (el objeto a transferir), la obtención del conocimiento especializado y específico del proceso de transferencia que es propio de los mediadores de la transferencia desde las oficinas de transferencia y desde los centros de creación de conocimiento. Eso no impide reconocer, al mismo tiempo, que algunas de las actividades más comunes utilizadas como transferencia son realizadas por los profesores de universidad, por ejemplo: la traducción del conocimiento, la transferencia de conocimientos, el intercambio de conocimientos, las prácticas de ese conocimiento creado, utilización de la investigación, la visualización de sus aplicaciones, la divulgación, la diseminación y la difusión del conocimiento creado. Pero de ahí a convenir que la transferencia es una función más de los profesores de universidad, hay un camino muy largo y un complejo proceso que afecta a intereses, derechos y desarrollo de competencias de 
los profesores que no se resuelven sin coste, ni sin cambios en la organización de los recursos humanos de la universidad.

La gestión del conocimiento es una tarea profesional que utiliza como instrumento el conocimiento creado por los investigadores. Que sea vista esa tarea como una función más de la profesión de profesor universitario que implica por el momento funciones de docencia, investigación, gestión administrativa y representación institucional, es algo que no se puede establecer sin más. No hay coste cero en esta atribución y tampoco es de recibo desde el punto de vista de la competencia a utilizar que se habilite una forma de evaluar la transferencia de conocimiento y que no se haya habilitado antes un programa de formación de profesores, para el logro de las competencias se requieren para hacer la transferencia. No es lo mismo y es un error grosero de consecuencias injustas para el mérito y la competencia no distinguir entre conocimientos transferibles, creados por los profesores de universidad en el ejercicio de sus funciones profesionales, y transferencia de conocimiento, que es una tarea especializada, distinta de la crear conocimiento.

Necesitamos que la transferencia de conocimiento sea una tarea institucionalmente asumida desde los centros y no solo desde las universidades. La especificidad de la tarea por áreas y por materias nos exige dotar plazas de personal mediador, que dinamice la transferencia y haga el papel técnico.

Un profesor no es un transferidor, pero su trabajo tiene valor de transferencia y hay personal especializado que podría ejercer esa tarea con competencia. No se puede renunciar al dinamizador de la transferencia, al transferidor técnico y a la transferencia de la universidad como institución, que tiene la obligación legal de determinar y establecer los medios e instrumentos necesarios para facilitar la prestación de este servicio social por parte del personal docente e investigador.

Si estuviéramos en el sistema universitario anglosajón, cada profesor cobraría por cada trabajo de investigación hecho y sería la universidad, institucionalmente la que se responsabilizaría de la transferencia. En nuestro sistema, dado que la mentalidad de evaluación de sexenios ya se ha transferido (en el sentido psicológico del término) a la mentalidad de los profesores, es justo reconocer que hay actividades de cada profesor evaluables como transferencia de conocimiento, atendiendo a la relación de esas actividades con la innovación de proceso, de producto y de organización y sin que eso implique renunciar al dinamizador de la transferencia, al transferidor técnico y a la transferencia de la universidad como institución, que, como especifica la legislación, tiene la obligación legal de determinar y establecer los medios e instrumentos necesarios para facilitar la prestación de este servicio social por parte del personal docente e investigador.

Así, la Ley de Universidades modificada, de 2007, contempla en diferentes artículos que (Ley Orgánica 4/2007, de 12 de abril, por la que se modifica la Ley Orgánica 6/2001, de 21 de diciembre, de Universidades. BOE 89, de 13 de abril de 2007, https://www.boe.es/boe/dias/2007/04/13/pdfs/A16241-16260.pdf):

39. “La universidad desarrollará una investigación de calidad y una gestión eficaz de la transferencia del conocimiento y la tecnología, con los objetivos de 
contribuir al avance del conocimiento y del desarrollo tecnológico, la innovación y la competitividad de las empresas, la mejora de la calidad de vida de la ciudadanía, el progreso económico y social y un desarrollo responsable equitativo y sostenible, así como garantizar el fomento y la consecución de la igualdad".

41. "La vinculación entre la investigación universitaria y el sistema productivo, como vía para articular la transferencia de los conocimientos generados y la presencia de la universidad en el proceso de innovación del sistema productivo y de las empresas, prestando especial atención a la vinculación con el sistema productivo de su entorno. Dicha vinculación podrá, en su caso, llevarse a cabo a través de la creación de empresas de base tecnológica a partir de la actividad universitaria, en cuyas actividades podrá participar el personal docente e investigador de las universidades conforme al régimen previsto en el artículo 83".

En la legislación está expresada con claridad la valoración de la transferencia, hasta el extremo de definir, no solo la importancia y las consecuencias que se derivan de esta función, sino también la dedicación y reconocimiento que merece la transferencia:

42. "La transferencia del conocimiento es una función de las universidades. Estas determinarán y establecerán los medios e instrumentos necesarios para facilitar la prestación de este servicio social por parte del personal docente e investigador. El ejercicio de dicha actividad dará derecho a la evaluación de sus resultados y al reconocimiento de los méritos alcanzados, como criterio relevante para determinar su eficiencia en el desarrollo de su actividad profesional".

Y, por último, en la vigente Ley 14/2011, de 1 de junio, de la Ciencia, la Tecnología y la Innovación, en su Artículo 32, referente a la Dedicación del personal docente e investigador, establece que (Ley 14/2011, de 1 de junio, de la Ciencia, la Tecnología y la Innovación.BOE, 131, de 2 de junio de 2011; https://www.boe.es/eli/ es///2011/06/01/14/con):

32. "Las Universidades públicas, en el ejercicio de su autonomía, podrán establecer la distribución de la dedicación del personal docente e investigador a su servicio en cada una de las funciones propias de la Universidad"

La transferencia es institucional y es también individual. Los organismos institucionales no han hecho nada por ahora para dotar plazas en centros que sirvan de dinamizadores de la transferencia (algo que la ley da por sentado como necesario). Se ha evaluado al profesor como transferidor, antes de establecer programas de formación y plazas de dinamizadores de transferencia en los centros. El desamparo de los profesores universitarios ante este tema es grande y de graves consecuencias. Añadir funciones a la tarea profesional sin consenso previo y dar por supuesta la competencia en la nueva función, es demasiado suponer. 


\section{REFERENCIAS BIBLIOGRÁFICAS}

Alburquerque, F. (2008). Innovación, transferencia de conocimientos y desarrollo económico territorial: una política pendiente. Arbor. Ciencia, Pensamiento y Cultura, 184(732), 687-700.

Almarcha, A. (2001). Misión de la universidad. Enseñanza superior y competitividad: la globalización de los mercados. Reis, 93, 205-220.

Almarcha, A. (2002). Nuevas titulaciones en relación con el mercado de trabajo y el uso de nuevas tecnologías. Informe final. Documento policopiado. Universidad de A Coruña.

Arendt, H. (1996). La crisis en la educación. En H. Arendt, Entre el pasado y el futuro. Ocho ejercicios sobre reflexión política. Barcelona: Península. (original de 1954), pp. 269-301.

Arias, J. E. y Aristizábal, C. A. (2011). Transferencia del conocimiento orientada a la innovación social en la relación ciencia-tecnología y sociedad. Revista científica Pensamiento y Gestión, 31, 137-166. Recuperado de http://rcientificas.uninorte. edu.co/index.php/pensamiento/article/view/3664/4992

Astigarraga, E. (2019). Universidad, competencias y mundo del trabajo. Recuperado de https://www.universidadsi.es/universidad-competencias-y-mundo-del-trabajo/

Barro, S. (2019). La universidad y la empresa aún no se besan. Recuperado de https:// www.universidadsi.es/la-universidad-y-la-empresa-aun-no-se-besan/

Bayona, C. y González, R. (2010). La transferencia del conocimiento en la universidad de navarra. Pamplona: Universidad Pública de Navarra.

Bekkers, R. y Bodas, I. (2008). Analysing Knowledge Transfer Channels between Universities and Industry: to What Degree Do Sectors Also Matter? Research Policy, 37, 1837-1853. Recuperado de http://www.sciencedirect.com/science/article/pii/ S0048733308001558

Bell, D. (1973). The Coming of Post-Industrial Society: A Venture in Social Forecasting. Nueva York: Basic Books.

Berbegal, J. (2017). Colaboración universidad-empresa, sí, pero ¿bajo qué condiciones? Recuperado de http://www.universidadsi.es/colaboracion-universidad-empresa-condiciones/

Bermejo, J. C. (2018). ¿Cuál es la relación económica entre científicos y el mercado editorial? Recuperado de Universidad sí, el 21 de febrero de 2018 de la página http://www.universidadsi.es/cual-es-la-relacion-economica-real-entre-cientificosy-el-mercado-editorial/

Bozeman, B. (2000). Technology Transfer and Public Policy: A Review of Research and Theory. Research Policy, 29(4), 627-655. Recuperado de http://calitc.pbworks. com/f/TechTransferStudy.pdf

Broncano, F. (2019). La universidad en funciones. Recuperado de https://www.universidadsi.es/la-universidad-en-funciones/ 
Bueno, E. (2007). La tercera misión de la universidad: El reto de la Transferencia del conocimiento. Revista madri+d, 41. Recuperado de https://www.madrimasd.org/ revista/revista41/tribuna/tribuna2.asp

Bueno, E. y Casani, F. (2007). La tercera misión de la universidad. Enfoques e indicadores básicos para su evaluación. Revista Economía Industrial, 366, 43-59.

Carayannis, E. G. y Campbell, D. F. J. (2009). "Mode 3" and "Quadruple Helix": Toward a 21st Century Fractal Innovation Ecosystem. International Journal of Technology Management, 46(3/4), 201-234. Recuperado de https://www.inderscience. com/info/inarticletoc.php?.jcode $=$ ijtm $\&$ year $=2009 \& \mathrm{vol}=46 \&$ issue $=3 / 4$

Carayannis, E. G. y Campbell, D. F. J. (2010). Triple Helix, Quadruple Helix and Quintuple Helix and How Do Knowledge, Innovation and the Environment Relate To Each Other? A Proposed Framework for a Trans-disciplinary Analysis of Sustainable Development and Social Ecology. International Journal of Social Ecology and Sustainable Development, 1(1), 41-69. Recuperado de http://www.igi-global. com/bookstore/article.aspx?titleid=41959

Carayannis, E. G. y Campbell, D. F. J. (2012). Mode 3 Knowledge Production 1 in Quadruple Helix Innovation Systems, Twenty-first-Century Democracy, Innovation, and Entrepreneurship for Development. SpringerBriefs in Business, 7. Recuperado de https://www.springer.com/la/book/9781461420613

Castells, M. (2001). La era de la información. La sociedad red. Madrid: Alianza Editorial.

Clark, B. (1998). Creating Entrepreneurial Universities: Organisational Pathways of Transformation. Nueva York: International Association of Universities and Elsevier Science.

Claxton, G. (2001). Aprender. El reto del aprendizaje continuo. Buenos Aires: Paidós.

Comisión de las Comunidades Europeas (1995a). Einseigner et appendre. Vers la societé cognitive. Libro blanco Bruselas, 29.11.1995. COM(95) 590 final. Recuperado de http://eur-lex.europa.eu/LexUriServ/LexUriServ. do?uri=COM:1995:0590:FIN:ES:PDF

Comisión de las Comunidades Europeas. (1995b). Libro Verde de la Innovación. Bruselas: ES/13/95/55220800.P00 (FR) aq/rc. Recuperado de sid.usal.es/idocs/F8/ FDO11925/libroverde.pdf

Comisión de las Comunidades Europeas. (2003). El papel de las universidades en la Europa del conocimiento. Recuperado de https://eur-lex.europa.eu/LexUriServ/ LexUriServ.do?uri=COM:2003:0058:FIN:ES:PDF

Comisión de las Comunidades Europeas. (2004a). Innovation Management and the Knowledge-Driven Economy. Brussels-Luxembourg: ECSC-EC-EAEC.

Comisión de las Comunidades Europeas. (2004b). The Europe of Knowledge 2020: A vision for University-Based Research and Innovation. Recuperado de https://www. forskningsradet.no/csstorage/flex_attachment/LiegeKonferanse0404.pdf 
Comisión de las Comunidades Europeas (2005a). Decisión del parlamento europeo y del consejo relativa al Séptimo Programa Marco de la Comunidad Europea de Acciones de Investigación, Desarrollo Tecnológico y Demostración (2007 a 2013). Triángulo del conocimiento. Bruselas, 6.4.2005 COM(2005) 119 final. Recuperado de https://eurlex.europa.eu/legal-content/ES/TXT/PDF/?uri=CELEX:52005PC0119(01)\&from=NL

Comisión de las Comunidades Europeas (2005b). Movilizar el capital intelectual de Europa: crear las condiciones necesarias para que las universidades puedan contribuir plenamente a la estrategia de Lisboa. Triángulo del conocimiento. Bruselas, 20.4.2005 COM(2005) 152 final. Recuperado de https://eur-lex.europa.eu/legalcontent/ES/TXT/PDF/?uri=CELEX:52005DC0024\&from=EN

Comisión de las Comunidades Europeas (2005c). Conclusiones del Consejo y de los Representantes de los Gobiernos de los Estados miembros reunidos en el seno del Consejo de 26 de noviembre de 2009 sobre el desarrollo del papel de la educación en un "triángulo del conocimiento» que funcione plenamente. Diario oficial de la Unión Europea 12-12-2009(2009/C 302/03. Recuperado de https://eur-lex. europa.eu/LexUriServ/LexUriServ.do?uri=OJ:C:2009:302:0003:0005:ES:PDF

Comisión de las Comunidades Europeas (2005d). Movilizar el capital intelectual de Europa: crear las condiciones necesarias para que las universidades puedan contribuir plenamente a la estrategia de Lisboa Bruselas, 20.4.2005, COM(2005) 152 final. Recuperado de https://eur-lex.europa.eu/legal-content/ES/TXT/PDF/?uri=CE LEX:52005DC0024\&from=EN

Comisión de las Comunidades Europeas (2009). Conclusiones del Consejo y de los Representantes de los Gobiernos de los Estados miembros reunidos en el seno del Consejo de 26 de noviembre de 2009 sobre el desarrollo del papel de la educación en un "triángulo del conocimiento» que funcione plenamente. Diario oficial de la Unión Europea, 12.12.2009 (2009/C 302/03). Recuperado de https://eur-lex. europa.eu/LexUriServ/LexUriServ.do?uri=OJ:C:2009:302:0003:0005:ES:PDF

Comisión de las Comunidades Europeas. (2010). EUROPA 2020. Una estrategia para un crecimiento inteligente, sostenible e integrador Bruselas, 3.3.2010. $\operatorname{COM}(2010) 2020$ final. Recuperado de https://eur-lex.europa.eu/legal-content/ES/ TXT/?uri=celex\%3A52010DC2020

Comisión de las Comunidades Europeas. (2011). Libro Verde. Del reto a la oportunidad: hacia un marco estratégico común para la financiación de la investigación y la innovación por la UE. Bruselas, 9.2.2011 COM(2011) 48 final.

Conesa, F. (2019). Transferencia versus transmisión de conocimiento: los nuevos sexenios. Recuperado de https://www.universidadsi.es/transferencia-versus-transmision-de-conocimiento-los-nuevos-sexenios/

Coombs, Ph. H. (1978). La crisis mundial de la educación. Barcelona: Península.

CRUE (2018). Transferencia de conocimiento. Nuevo modelo para su prestigio e impulso. Madrid: CRUE-Santander universidades. (Coordinador del grupo de trabajo, Salustiano Mato). 
Díaz-Barriga, F. (2010). Los profesores ante las innovaciones curriculares Revista Iberoamericana de Educación Superior RIES, 1(1), 2010, 37-57. http://www.scielo. org.mx/pdf/ries/v1n1/v1n1a4.pdf

Drucker, P. (1993). Post-Capitalist Society. Oxford: Butterworth-Heinemann.

Drucker, P. (1969). The Age of Discontinuity. Nueva York: Harper and Row.

Echeverría, J. (1999). Los señores del aire: Telépolis y el tercer entorno. Barcelona: Destino.

Esteve, J. M. (2010a). La tercera revolución educativa. La educación en la sociedad del conocimiento. Madrid: Paidós.

Esteve, J. M. (2010b). Educar: un compromiso con la memoria. Un libro para educar en libertad. Barcelona: Octaedro.

Etzkowitz, H. y Leydesdorff, L. (1995). The Triple Helix-University-Industry-Government Relations: A Laboratory for Knowledge-Based Economic Development, EASST Review, 14(1), 14-19. Recuperado de https://papers.ssrn.com/sol3/papers. cfm?abstract_id=2480085

Faure, E. (1973). Aprender a ser. Madrid: Alianza.

Fontela, E. (2001). La globalización, tendencias económicas e implicaciones sociales. En A. Sáenz de Miera (Coord.), En torno al trabajo universitario (pp. 43-57). Madrid: Consejo de Universidades.

Fraser, A. G. y Dunstan, F. D. (2010). On the Impossibility of Being Expert. BMJ 2010;341:c6815. https://www.bmj.com/content/341/bmj.c6815.full

García Guadilla, C. (Coord.) (2004). El difícil equilibrio: la educación superior como bien público y comercio de servicios (Documentos Columbus sobre la gestión universitaria). Cuenca: Ediciones de la Universidad de Castilla-La Mancha.

García, D. (2019). La conexión universidad-empresa, vista desde la empresa. Recuperado de https://www.universidadsi.es/la-conexion-universidad-empresa-vistadesde-la-empresa/

Gibb, A. (1993). The enterprise culture and education: understanding enterprise education and its links with small business, entrepreneurship and wider educational goals. International Small Business Journal, 11(3), 14-34.

Gibbons, M. (1998). Higher Education Relevance in the 21st Century. Paris: UNESCO World Conference on Higher Education.

Gibbons, M., Limoges, C., Nowotny, H., Schwartzman, S., Scott, P. y Trow, M. (1994). The New Production of Knowledge. Londres: Sage.

Gómez Sal, J. C. (2016). La función de transferencia en las universidades: algunas ideas sobre indicadores clave y su aplicabilidad. Recuperado de http://www.universidadsi.es/la-funcion-transferencia-las-universidades-algunas-ideas-indicadores-clave-aplicabilidad-i/ 
González, T. de la (2009). El modelo de Triple Hélice de relaciones universidad, industria y gobierno: un análisis crítico. Arbor. Ciencia, Pensamiento y Cultura, 185(738), 739-755. Recuperado de http://arbor.revistas.csic.es/index.php/arbor/ article/view/327

Haug, G. y otros (2018). Universidades y empresas. Apuntes para crear sinergias con sentido. Madrid: Fundación Europea Sociedad y Educación.

Herrera, E., Bonilla, H. y Molina, L. F. (2013). Ciudades creativas: ¿paradigma económico para el diseño y la planeación urbana? Revista Bitácora Urbano Territorial, 22(1), 11-20.

Hidalgo, A., León, G. y Pavón, J. (2002). La gestión de la innovación y la tecnología en las organizaciones. Madrid: Ediciones Pirámide.

Huberman, A. M. (1973). Cómo se realizan los cambios en la educación: una contribución al estudio de la innovación. París: UNESCO.

Husén, T. (1978). La sociedad educativa. Madrid: Anaya.

Hutchins, R. (1968). The Learning Society. Londres: Penguin.

López, O., Blanco, M. y Guerra, S. (2009). Evolución de los modelos de la gestión de innovación. Innovaciones de Negocios, 5(2), 251-264.

Luque, R. (2016). ¿Fin de la iniciativa de Campus de Excelencia Internacional (CEI)? Recuperado de http://www.universidadsi.es/fin-la-iniciativa-campus-excelenciainternacional-cei/

Luque, T. (2018). Universidad "Blockchain". Recuperado de http://www.universidadsi.es/universidad-blockchain/

Martín, C. y otros (1986). Investigación, innovación y tecnología. Investigación, innovación y tecnología. (Biblioteca de Economía Española).Barcelona: Orbis.

Martínez, A. (2008). Modelos de innovación: un análisis integral. Primer Seminario Nacional de Economía Institucional. Recuperado de https://www.researchgate. net/publication/313427240

Martínez-Gómez, J. (2017). Procesos de transferencia del conocimiento en una Facultad de Ciencias Contables. Revista Espacios, 38(50), 1-7. Recuperado de https:// www.revistaespacios.com/a17v38n50/a17v38n50p01.pdf

Matía, N. (2015). Estrategia Europa 2020 la estrategia europea para un crecimiento inteligente, sostenible e integrador. Derecho y cambio social, 1-17. Recuperado de http://www.derechoycambiosocial.com

Messadié, G. (1999). Grandes descubrimientos de la ciencia. Madrid: Alianza Editorial.

Messadié, G. (2000a). Grandes inventos de la humanidad (hasta 1850). Madrid: Alianza Editorial.

Messadié, G. (2000b). Grandes inventos del mundo moderno (desde 1850). Madrid: Alianza Editorial. 
Molero, J. (2008). La transferencia de tecnología revisada: conceptos básicos y nuevas reflexiones a partir de un modelo de excelencia de gestión. Arbor. Ciencia, Pensamiento y Cultura, 184(732), 637-651.

Neira, T. R. (2011). Hacia una nueva civilización. Los muros de la escuela y el asedio de los bits. Oviedo: Universidad de Oviedo.

Nieto, J. (2008). Y tú, ¿innovas o abdicas? Valencia: Universidad Politécnica de Valencia.

Nowotny, H., Scott, P. y Gibbons, M. (2001). Re-thinking Science, Knowledge and the Public in An Age of Uncertainty. Cambridge: Oxford: Polity Press.

OMS (2007). Ciudades globales amigables con los mayores: una guía. Ginebra: Organización Mundial de la Salud.

Ortega y Gasset, J. (1968a). Misión de la Universidad. Madrid: Revista de Occidente.

Ortega y Gasset, J. (1968b). El tema de nuestro tiempo. Madrid: Espasa-Calpe, Austral, $12^{a}$ ed. (Fecha edición original, 1934 y la primera parte del libro se corresponde con la lección inaugural de su curso universitario 1921-22).

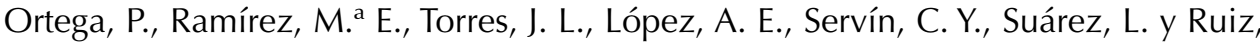
B. (2007). Modelo de innovación educativa. Un marco para la formación y el desarrollo de una cultura de la innovación. RIED, 10(1), 145-173. Recuperado de http://www.biblioteca.org.ar/libros/142346.pdf

Padmore, T., Schuetze, H. y Gibson, H. (1998). Modeling Systems of Innovation: An Enterprise-Centered View. Research Policy, 26, 605-624.

Pérez Díaz, V. y Rodríguez, J. C. (2002). La educación profesional en España. Madrid: Fundación Santillana.

Pirnay, F., Surlemont, B. y Nlemvo, F. (2003). Toward a Typology of University Spinoff. Small Business Economics, 21(4), 355-365.

Porta, J. y Lladonosa, M. (Coords.) (1998). La universidad en el cambio de siglo. Madrid: Alianza Editorial.

Potocnik, J. (2009). The significance of the knowledge triangle for the future of Europe European. Speech by The Commissioner for Science and Research J. Potocnik europa. eu/rapid/press-release_SPEECH-09-355_en.pdf (Conference organised by the Swedish Presidency) The Knowledge Triangle Shaping the Future of Europe - Conference Conclusions. Gothenburg, 1 de septiembre de 2009. Recuperado de https://www.uka. se/download/18.12f25798156a345894e2bbb/1487841904645/0926R.pdf

Pulido, A. (2009). El futuro de la universidad. Un tema para debate dentro y fuera de las universidades. Madrid: Delta. Recuperado de http://www.univnova.org/libro/ pdf/el_futuro_de_la_universidad.pdf

Ramos, M. ${ }^{\text {a }}$ (2019). La formación en Empresas y Universidades, también a lo largo de la vida. Recuperado de https://www.universidadsi.es/la-formacion-en-empresas-yuniversidades-tambien-a-lo-largo-de-la-vida/ 
Rodríguez, P. (2017). La misión social de la universidad, más allá de la transferencia del conocimiento. Recuperado de http://www.universidadsi.es/la-mision-socialla-universidad-mas-alla-la-transferencia-del-conocimiento/

Salaburu, P. (2017). Universidad y empresa. ¿Dos mundos? Recuperado de http:// www.universidadsi.es/universidad-empresa-dos-mundos/

Salorio, M. S. (1993). Universidade, multiversidade, megaversidade. Santiago de Compostela: Universidad de Santiago de Compostela.

Scheffler, I. (1970). El lenguaje de la educación. Buenos Aires: El Ateneo.

Sebastián, J. (2008). La transferencia de conocimientos en la cooperación al desarroIlo. Arbor. Ciencia, Pensamiento y Cultura, 184(732), 719-728.

SI(e)TE (2012). Creatividad, educación e innovación: emprender la tarea de ser autor y no sólo actor de sus propios proyectos. Revista de Investigación en Educación, 10(1), 7-29.

SI(e)TE (2013). Educación, Crítica y desmitificación de la educación actual (pp. 5792). Barcelona: Octaedro. (¿Enseñar áreas culturales o educar con las áreas culturales?).

SI(e)TE (2014a). Educación y crisis económica actual (pp. 7-35). Barcelona: Horsori Editorial. (Crisis 'de' la educación, crisis 'en' la educación y crisis de valores: la educación en crisis).

SI(e)TE (2014b). Política y educación (Desafíos y propuestas) (pp. 105-143). Madrid: Dykinson. (La acción de la sociedad civil no es la acción política. Un problema de formación y no una nueva antinomia pedagógica).

SI(e)TE (2016). Repensar las ideas dominantes en la educación. Santiago de Compostela: Andavira.

SI(e)TE (2018). La pedagogía, hoy. Santiago de Compostela: Andavira.

SID (1997). ¿Qué globalización? Actas del Congreso mundial de la Sociedad Internacional para el Desarrollo. Santiago de Compostela: Xunta de Galicia.

SID (2000). Globalization and Knowledge Society: Expert Meeting. Santiago de Compostela: IGACI.

Slaughter, S. y Leslie, L. (1997). Academic Capitalism: Politics, Policies and the Entrepreneurial University. Baltimore: John Hopkins University Press.

Solá, F. (2002). La organización de la universidad ante la nueva economía. En A. Sáenz de Miera (Coord.), La universidad en la nueva economía (pp. 55-76). Madrid: Consejo de Universidades.

Spackman, P. (1973). ¿Son necesarias las escuelas? Facetas, 5(4), 23-33.

Telford, R. (1990). Escuela e industria. Dictamen IRDAC (Industrial Research and Development Advisory Commission). Grupo XI. Comisión de las Comunidades Europeas. Bruselas. 
Torres, J. (2011). La justicia curricular. El caballo de Troya de la cultura escolar. Madrid: Morata.

Touriñán, J. M. (1996a). Nuevas tendencias en el desarrollo universitario: el efecto Maastricht. XI Congreso Nacional de Pedagogía. Sociedad Española de Pedagogía. Donostia. Tomo III, pp.165-190.

Touriñán, J. M. (1996b). Sistema Universitario de Galicia. Fundamentos e desenvolvemento legal (Colección Innovación e Investigación Científica). Santiago de Compostela: Xunta de Galicia.

Touriñán, J. M. (1997a). Directrices comunitarias de la educación universitaria: crisis de la institución y estrategias de innovación. Revista Galego-portuguesa de Psicoloxía e educación, 1, 9-32.

Touriñán, J. M. (1997b). La consolidación del sistema universitario y de la comunidad científica en Galicia. Propuestas de Análisis. Santiago de Compostela: Grafinova.

Touriñán, J. M. (2000a). Globalización y desarrollo: un reto de las políticas regionales de IDT. IX Cumbre Iberoamericana de Jefes de Estado y de Gobierno. Ponencias de la Conferencia científica (pp. 219-249). La Habana: CYTED. Publicado también en Santiago de Compostela: Centro de Investigación Económica y financiera (CIEF), Documentos de Economía, (8), 5-65.

Touriñán, J. M. (2000b). Sociedad de la información, políticas regionales y desarrollo de planes estratégicos de IDT. En J. M. Touriñán y A. Bravo, Gestión de política científica y recursos de investigación (pp. 9-40). Santiago de Compostela: IGACI.

Touriñán, J. M. (2008). Decisión política y politización de la decisión: complejidad estructural de la decisión en política educativa. En J. Evans, y E. Kristensen, (Eds.), Investigación, desenvolvemento e innovación (pp. 11-50). Santiago: USC.

Touriñán, J. M. (2014). Dónde está la educación. Actividad común interna y elementos estructurales de la intervención. A Coruña: Netbiblo. Recuperado de http:// dondestalaeducacion.com

Touriñán, J. M. (2015). Pedagogía mesoaxiológica y concepto de educación. Santiago de Compostela: Andavir.

Touriñán, J. M. (2016). Pedagogía general. Principios de educación y principios de intervención. A Coruña: Bello y Martínez.

Touriñán, J. M. (2017). Mentalidad pedagógica y diseño educativo. De la pedagogía general a las pedagogías aplicadas en la función de educar. Santiago de Compostela: Andavira.

Touriñán, J. M. (2018). Concepto de educación y conocimiento de la educación. The Concept of Education and the Knowledge of Education. Ann Arbor (Michigan)Cali (Colombia): ProQuest (Bowker Books in Print)-Redipe.

Touriñán, J. M. y Bravo, A. (Eds.) (2000). Gestión de política científica y recursos de investigación. Santiago de Compostela: Instituto Galego de Cooperación Iberoamericana. 
Touriñán, J. M. y Sáez, R. (2015). La mirada pedagógica. Teoría de la educación, metodología y focalizaciones. Santiago de Compostela, Andavira.

Trott, P. (2002). Innovation Management and New Product Development. Essex, UK: Prentice Hall. (2nd ed.).

Úbeda, V. (2013). El principio de transferencia del entrenamiento. Recuperado de https:// educadamentesite.wordpress.com/2016/01/07/la-transferencia-del-aprendizaje/

UNESCO. (1997). Nuestra diversidad creativa. Informe de la Comisión mundial de Cultura y Desarrollo. Madrid: UNESCO-SM. Fundación Santa María.

UNESCO. (2005). Hacia las sociedades del conocimiento. París: UNESCO. http:// unesdoc.unesco.org/images/0014/001419/141908s.pdf

UNESCO. (2011a). UNESCO y la educación. Hacia unos indicadores de alfabetización informacional. Paris: UNESCO. Recuperado de https://unesdoc.unesco.org/ ark:/48223/pf0000212715_spa

UNESCO. (2011b). Compendio mundial de la educación 2011. Comparación de las estadísticas de la educación en el mundo. Canadá-Montreal-Quebec: Instituto de Estadística de la UNESCO. Recuperado de http://uis.unesco.org/sites/default/files/ documents/global-education-digest-2011-comparing-education-statistics-acrossthe-world-sp.pdf

UNESCO. (2008). Hacia unos indicadores de alfabetización informacional. Paris: División de la Sociedad de la Información.

Upstill, G. y Symington, D. (2002). Technology Transfer and the Creation of Companies: the CSIRO Experience. R\&D Management, 32(3), 233-239.

Velasco, E., Zamanillo, I. y Intxaurburu, G. (2007). Evolución de los modelos sobre el proceso de innovación: desde el Modelo lineal hasta los Sistemas de innovación. XX Congreso anual de AEDEM. 2. Palma de Mallorca: Asociación Europea de Dirección y Economía de Empresa. Recuperado de https://www.researchgate.net/ publication/28200735

Vidal, J. (2018). ¿Qué es esto de la tercera misión? Recuperado de http://www.universidadsi.es/la-tercera-mision/

Vilalta, J. (2013). La tercera misión universitaria. Innovación y transferencia de conocimientos en las universidades españolas. Madrid: Fundación Española Sociedad y Educación.

Vilalta, J. M. (2016). Conectando formación, investigación e innovación. Recuperado de http://www.universidadsi.es/conectando-formacion-investigacion-e-innovacion/

Wirt, F. M. y Harman, G. (1987). La recesión internacional y la política educativa. Comparación de las políticas educativas nacionales y las corrientes internacionales. Revista de Educación, 283, 5-28.

Ziman, J. (1994). Prometeus Bound: Science in a Dynamic Steady State. Cambridge (U.K.): Cambridge University Press. 